Revista lus et Praxis, Año 21, No 1, 2015, pp. 271 - 314

ISSN 0717 - 2877

Universidad de Talca - Facultad de Ciencias Jurídicas y Sociales

"La constitucionalización de los derechos sexuales y reproductivos.

Hacia una igual ciudadanía para las mujeres"

Cecilia Valenzuela Oyaneder - Luis Villavicencio Miranda

Trabajo recibido el 11 de septiembre y aprobado el 12 de diciembre de 2014

\title{
La constitucionalización de los derechos sexuales y reproductivos. Hacia una igual ciudadanía para las mujeres*
}

\section{THE CONSTITUTIONALIZATION OF SEXUAL AND REPRODUCTIVE RIGHTS. TOWARDS AN EQUAL CITIZENSHIP FOR WOMEN}

\author{
Cecilia Valenzuela Oyaneder** \\ LUIS VILLAVICENCIO MIRANDA***
}

RESUMEN

En este artículo nos proponemos, en primer lugar, contextualizar la falta de pertenencia de las mujeres a la comunidad constitucional, específicamente respecto del ejercicio de sus derechos sexuales y reproductivos y de un derecho al aborto, examinando la conexión (o inconexión) que la jurisprudencia comparada ha trazado entre el derecho al aborto y el derecho constitucional a la igualdad y la dignidad. En segundo lugar, desde una perspectiva feminista, construiremos un argumento, fundado en el enfoque de las capacidades, que justifique la constitucionalización de los referidos derechos sexuales y reproductivos.

\section{ABSTRACT}

In this article we propose, first, to contextualize the lack of women membership to the constitutional community, specifically with regard to the exercise of their sexual and reproductive rights and abortion rights, analyzing the connection (or inconnection) that comparative jurisprudence has drawn between the right to abortion and the constitutional right to equality and dignity. Second, from a feminist perspective, we will construct an argument, based on the capability approach, to justify the constitutionalization of the mentioned sexual and reproductive rights.

PALABRAS CLAVE

Constitución, Mujeres, Derechos sexuales y reproductivos, Feminismo, Igualdad

KEYWORDS

Constitution, Women, Sexual and reproductive rights, Feminism, Equality

\footnotetext{
* Este artículo forma parte del Proyecto Fondecyt Regular № 120566 titulado "Ciudadanía para las mujeres en una sociedad multicultural. Hacia la construcción de una concepción deliberativa con vocación universal y su impacto institucional".

** Universidad de Playa Ancha, Valparaíso, Chile. Doctoranda en Derecho (Universidad Diego Portales, Santiago de Chile). Dirección postal: Avenida Playa Ancha 850, Valparaíso, Chile. Correo electrónico: valenzuelaoyaneder@gmail.com.

*** Profesor e investigador Escuela de Derecho de la Universidad de Valparaíso, Valparaíso, Chile. Profesor titular de Introducción al Derecho. Doctor en Derecho. Dirección postal: Errázuriz 2120, Valparaíso, Chile. Correo electrónico: luis.villavicencio@uv.cl.
} 


\section{Introducción}

El 21 de mayo del año 2014 la presidenta Bachelet anunció que debe debatirse en el Parlamento un proyecto de ley para despenalizar la interrupción voluntaria del embarazo en los casos de riesgo para la vida de la madre, violación $\mathrm{o}$ inviabilidad fetal ${ }^{1}$. Teniendo en cuenta la presión social ${ }^{2}$ e internacional ${ }^{3}$ que pesa sobre Chile por criminalizar el aborto a todo evento, el futuro proyecto -O los que definitivamente sean patrocinados por el ejecutivo de los actualmente pendientes ${ }^{4}$ - es tremendamente relevante pues sitúa en el tapete un tema que la doctrina constitucional ha dejado de lado sistemáticamente: la necesidad de constitucionalizar los derechos sexuales y reproductivos de las mujeres.

Esta omisión constitucional no es una sorpresa. Las constituciones, en general, carecen de neutralidad desde una perspectiva de género para regular aquellas cuestiones fundamentales relacionadas con la organización social y la vida política de quienes pertenecen a la comunidad política, mujeres y hombres. La propia universalidad del Derecho basada en la doctrina legal, política y filosófica desarrollada desde 1789 en la Francia Revolucionaria, nunca ha sido tal. La creación y lectura del Derecho siempre han sido en clave masculina, y ello quedó de manifiesto ya en el siglo XVIII durante el período de la Ilustración al vindicarse la individualidad, la autonomía de los sujetos y los derechos referidos solo a la mitad de la especie humana, los hombres. Esto, como puede suponerse, ha traído consigo múltiples escollos para incluir la perspectiva de género en el mundo jurídico, debido a su habilidad para reproducir el modelo

\footnotetext{
${ }^{1}$ Las palabras textuales de la presidenta fueron: "Chile tiene que enfrentar en una discusión madura, informada y propositiva esta realidad, debatiendo en el Parlamento un proyecto de ley que despenalice la interrupción voluntaria del embarazo en casos de riesgo de vida de la madre, violación e inviabilidad del feto" (Mensaje presidencial, página 28. Disponible en: http://21 demayo.gob.cl/pdf/2014_discurso21-mayo.pdf).

2 El apoyo mayoritario en Chile a la despenalización, al menos parcial, del aborto, es claro. Así, por ejemplo, según un estudio Flacso-Chile $(2011,87)$ el 67\% de la población está de acuerdo con la interrupción del embarazo en caso de peligro para la vida de la madre o violación y un $64 \%$ en caso de malformación fetal grave. En la reciente encuesta CEP del segundo semestre de 2014 los porcentajes son todavía más claros: $72 \%$ en el caso de peligro para la vida de la madre, $71 \%$ en el caso que el feto sea inviable y $70 \%$ en el caso de violación.

3 Solo a modo de ilustración, en el Informe del Grupo de Trabajo sobre el Examen Periódico Universal del Consejo de Derechos Humanos de la ONU del año 2014, nuestro país recibió 185 recomendaciones de 84 Estados. Todos los países que hicieron recomendaciones sobre el tema que aquí nos interesa recomendaron a Chile, sin excepción, revisar la penalización total del aborto. Ver: http://www.minrel. gob.cl/informe-epu-chile-2014-consejo-de-derechos-humanos/minrel/2013-08-07/164104.html.

${ }^{4}$ Actualmente en el Congreso se encuentran pendientes (primer trámite constitucional) dos mociones parlamentarias presentadas durante el año 2013, una en el Senado ( $N^{\circ}$ boletín 8862-11) y otra en la Cámara de Diputados ( $N^{\circ}$ boletín 8925-11), que coinciden con las causales indicadas en el discurso presidencial.
} 
de la dominación masculina y a su intención manifiesta (o implícita) de dejar a las mujeres apartadas del espacio público. Esta falsa universalidad del Derecho va inexorablemente acompañada de una ilusoria neutralidad desde la perspectiva de género, ya que al convocar solo a la población masculina, su normativa omite la otra mitad de la población, invisibilizando sus experiencias y homogenizándolas con la de los hombres.

Esta realidad es posible advertirla, incluso, en jurisprudencia relativamente reciente, como en "Estados Unidos v. Morrison" de una sección del Acta Federal Contra la Violencia de las Mujeres (VAWA) que creaba una acción civil federal para los crímenes de violencia basados en el género, cuando el procedimiento criminal estatal había fallado o las acciones civiles estatales no estuvieran disponibles. Al respecto, la Suprema Corte declaró que la Sección 13981 de la VAWA, era ultra vires, es decir, iba más allá del poder legislativo federal, y por consiguiente, era inválida constitucionalmente. La disposición de la igualdad contenida en la Decimocuarta Enmienda no daba facultad al Congreso para dictar una ley de esta naturaleza, ya que no era un escudo contra las conductas meramente privadas, aunque fueran abusivas o discriminatorias. La defensa del gobierno, basada en datos estadísticos, sostuvo que la violencia contra las mujeres era un asunto nacional, debido al detrimento que implicaba en la economía interestatal, por ello era necesaria una medida federal. Finalmente, la Corte sostuvo que, no obstante las cifras estadísticas, no había conexión entre los crímenes motivados en el género y el comercio interestatal. Cabe observar que el asunto de fondo, esto es, la violencia contra las mujeres, quedó relegada a lo menos importante. Lo impresentable de este caso es que la violencia contra la mujer no se entendió como un asunto de interés nacional. La experiencia común de las mujeres respecto de alguna violencia, o el miedo inhibidor de la violencia era demasiado privado para atraer un remedio público, como también insuficientemente sistémico o interconectado con su impacto para ser colectivo y para adquirir un carácter nacional en apoyo de una reparación privada. El caso Morrison nos invita a preguntarnos, respecto de lo que es verdaderamente nacional y dónde está el lugar de las mujeres y su experiencia en el esquema federal, si es que acaso tiene uno ${ }^{6}$.

La supuesta neutralidad aparece, además, en el lenguaje utilizado por las constituciones. Autoras como Sandra Peterson, afirman que históricamente el lenguaje masculino no ha pretendido ser neutral. Un buen ejemplo son los países del Commonlaw, en los que alrededor de la mitad del siglo XIX, la

5529 U.S. 598 (2000). Puede consultarse el fallo aquí: http://caselaw.lp. findlaw.com/scripts/getcase. pl?court=US\&vol=529\&invol=598 [visitado el 2/07/2014].

${ }^{6}$ IRVING (2008), pp. 65, 72-74. 
práctica del uso de términos masculinos que incluyeran a las mujeres no era absoluta y las cortes, a menudo, usaban el contexto para excluirlas. En efecto, por más trivial que parezca, el lenguaje legal puede hacer a la mujer y su experiencia invisible, mientras declara ser neutral e inclusivo, produciéndose una disonancia pragmática evidente entre el nivel locucionario e ilocucionario del discurso, de insospechadas consecuencias. Por ello, actualmente, los redactores de constituciones tratan de evitar especificaciones de género y prefieren usar sustantivos, evitando los pronombres y solo usan hombre o mujer, él o ella, cuando sea inevitable ${ }^{7}$.

Toda esta falsa neutralidad y las consecuencias de ésta se deben a la discriminación de carácter estructural que sufren las mujeres, y que las repliega a la esfera privada, a lo doméstico, y que prohíbe, algunas veces tácita otras expresamente, su ingreso al espacio público. Ahora, si llevamos esta histórica e involuntaria ausencia de las mujeres al terreno de los debates y tomas de decisión relacionadas con la redacción de las Constituciones, se hace difícil reconocerles legitimidad, en la medida que compartamos la idea de que "el consentimiento del pueblo - todo el pueblo- es una condición previa para la legitimidad constitucional $^{8}$, lo que trae consigo la falta de sentido de pertenencia de las mujeres a la que debería ser su comunidad política. Y es que resulta evidente que, si un sector de la sociedad es apartado involuntariamente de las deliberaciones en torno a las líneas fundamentales conforme a las cuales se organizará ésta (como puede ser el proceso de redacción de una nueva constitución), será muy difícil que dicho sector tenga, hacia la comunidad que supuestamente forma parte, un sentimiento de pertenencia que incluya "la posibilidad de crítica o reclamo por un cambio [ya que,] un miembro de la comunidad constitucional debe estar autorizado para reclamar acerca y en contra de la constitución, con la confianza de que ello será reconocido como el resultado de su legítimo interés en el asunto" ${ }^{\prime \prime}$. Luego, si las mujeres carecen de este sentimiento, la herramienta fundamental para velar por el reconocimiento, respeto y promoción de su autonomía, dignidad y respeto como persona, como debería ser la constitución, les será indiferente y ajena.

No obstante lo anterior, no debemos ignorar que, aun en estas condiciones de "pertenencia a medias" (si se nos permite la expresión) o "no pertenencia" a sus comunidades constitucionales, al revisar los orígenes de ciertas constituciones en el derecho comparado, las mujeres, desafiando la anquilosada estructura patriarcal de la toma de decisiones, han luchado con éxito por su integración

7 IRVING (2008), pp. 24-41.

8 IRVING (2008), p. 4.

9 IRVING (2008), p. 3. 
en los espacios de decisión. Tal es el caso de las norteamericanas en la redacción de la Convención de Filadelfia de 1787, ya que su falta de participación política no implicó que no tuvieran una opinión o punto de vista respecto de la nueva constitución. Por otra parte, a fines del siglo XVIII, la publicación de Mary Wollstonecraft de su obra Vindicación de los derechos de la Mujer en Inglaterra, en 1792, puso los cimientos para las campañas constitucionales de mujeres de las décadas venideras. Luego, en el siglo XIX, las norteamericanas fueron en gran parte agentes y sujetos de la Décima Tercera Enmienda, ratificada al término de la Guerra Civil en 1865, mediante la cual se eliminó la impunidad respecto de la esclavitud y la servidumbre involuntaria. Por otra parte, un ejemplo más cercano es el caso de Colombia en 1991, donde "a pesar de la escasa participación de la mujer en la asamblea constituyente (...) [ellas] y las organizaciones abocadas a sus causas se mantuvieron activas fuera de la asamblea. Como resultado de su trabajo, obtuvieron apoyo para muchos de sus temas de agenda (...) La Constitución de 1991 incluyó tres generaciones de derechos: civiles y políticos, sociales y colectivos, incluyendo muchos otros relacionados con la protección del género ${ }^{10}$. Nigeria es otro caso. A inicios del año 2004, un movimiento de mujeres, durante la revisión de la Constitución de 1999 elaboraron una serie de propuestas y recomendaciones que haría a la Constitución más amigable con las mujeres, entre las cuales plantearon la necesidad de la implementación de acciones positivas, así como también, que "la Constitución debía ser redactada en inglés básico y traducida a los idiomas locales para su fácil acceso"11.

No cabe duda que la única forma de superar la opresión estructural ${ }^{12}$ que padecen las mujeres es mediante la remoción de los obstáculos que han permitido y consolidado una sociedad y un Estado de derecho patriarcales. En ese escenario, serían indispensables, al menos, dos líneas de acción: por una parte, establecer mecanismos -como las cuotas electorales- que aseguren un acceso igualitario de las mujeres a los puestos de poder, con la esperanza de que ello

\footnotetext{
10 Morgan (2005), p. 76.

11 IRVING (2008), p. 17.

12 El término, acuñado por Young, gira en torno a un nuevo concepto de opresión que "designa las desventajas e injusticias que sufre alguna gente no porque un poder tiránico la coaccione, sino por las prácticas cotidianas y estructurales de una bien intencionada sociedad liberal". En particular, tratándose de las mujeres, la opresión consiste, en parte, en una transferencia sistemática y no recíproca de poderes a los hombres, que implica más que una desigualdad de estatus, poder y riqueza resultante de la práctica cultural por la cual los hombres han excluido a las mujeres de las actividades privilegiadas, ya que esa desigualdad es posible precisamente porque las mujeres trabajan para ellos. De este modo, la explotación de género se inicia con la transferencia a los hombres de los frutos del trabajo material y de las energías sexuales y de crianza de las mujeres lo que no se modificará a menos que lo haga la estructura social y cultural. Young (2000), pp. 89-93.
} 
pueda influir en una producción normativa que se haga cargo de las asimetrías estructurales de género ${ }^{13}$; y, por otra, la identificación, sistematización y contenido esencial de los derechos fundamentales necesarios para superar tales asimetrías. Esa sería, permítannos la licencia, la agenda larga ${ }^{14}$. El objetivo de este artículo es, sin embargo, más modesto: conscientes de esa agenda larga, lo que nos interesa aquí es más bien el ínterin (la agenda corta), esto es, reflexionar en torno al modo en que una reinterpretación de la cláusula de igualdad, especialmente por parte de la jurisdicción constitucional, puede contribuir a minar la falsa neutralidad de las reglas jurídicas mediante el reconocimiento y protección de los derechos sexuales y reproductivos como un componente crucial de una igualdad de trato entre los sexos. Como es obvio, la agenda corta no es inconsistente, sino complementaria (y en algún modo preparatoria) de la larga.

En este trabajo nos proponemos, entonces, presentar una posible lectura de la constitución, con sensibilidad de género, que facilite la efectiva incorporación igualitaria de las mujeres al demos, poniendo especial atención a la jurisprudencia comparada y al enfoque de las capacidades desarrollado por Nussbbaum, aplicado especialmente al reconocimiento constitucional de los derechos sexuales y reproductivos, incluido el derecho al aborto. Para ello, hemos dividido el artículo en cuatro partes. En la primera de ellas, queremos contextualizar el problema. En la segunda, exploramos una formulación del principio de igualdad sensible al género desde el enfoque de las capacidades. En la tercera, desarrollamos una serie de argumentos que, de manera consistente con la concepción de la igualdad defendida, permiten justificar un reconocimiento constitucional de los derechos sexuales y reproductivos de las mujeres. $\mathrm{Y}$, finalmente, cerramos el trabajo con algunas conclusiones.

\section{¿Cómo combatir la falta de pertenencia al demos?}

Esta falta de pertenencia, o "pertenencia a medias" a la comunidad constitucional, no se resuelve solo con la consagración de derechos constitucionales. Se requiere, además, de la decidida participación de la judicatura constitucional interpretando la constitución desde una postura feminista, acortando poco a poco la distancia que existe entre la comunidad constitucional y ellas ${ }^{15}$. Australia y

\footnotetext{
13 Sobre la discusión sobre la admisibilidad y pertinencia de las cuotas electorales deben verse ZúÑIGA Añazco (2005), pp. 131-154, Aguilera y ZúNiga Fajuri (2007), pp. 9-30; y Valenzuela y Zúñiga Fajuri (2014), pp. 191-211.

${ }^{14}$ Sobre estas cuestiones centrales son indispensables los trabajos de ZúÑIGa AÑAZCo (2006, 2009 y 2010).

15 Se trata de construir un bloque de constitucionalidad, esto es, el entramado de reglas y principios que, sin establecerse necesariamente de modo explícito en la constitución, son utilizados como parámetros del control de constitucionalidad de las leyes y estándares de protección de los derechos
} 
Canadá, por ejemplo, no necesitaron una carta de derechos ni tampoco alguna enmienda constitucional, como sí ocurrió en los EE.UU., para concederle el derecho a voto a las mujeres, no obstante tener similares sistemas democráticos y reglas de derecho en común. El rol interpretador fue la clave.

Por su parte, el propio derecho a la igualdad no siempre ha sido consagrado expresamente en las Constituciones y, en ocasiones, no ha sido necesario para su reconocimiento y respeto. Tal es el caso de Australia que tiene una constitución que omite en buena medida el lenguaje de los derechos y, sin embargo, la Corte Suprema vía jurisprudencial ha venido sosteniendo que la igualdad es el principio fundamental sobre el cual se funda la constitución. La igualdad de género, por su parte, ha sido abordada en el caso australiano, mediante la legislación federal y estatal. El gobierno federal de este país, sorteando su falta de capacidad explícita para regular sobre esta materia, se ha apoyado en los tratados internacionales existentes y en sus poderes en materia de relaciones exteriores contenidos en la Sección 51 de la Constitución. Además, la Corte Suprema ha dispuesto que, cuando es necesaria una ley para implementar un acuerdo internacional, el gobierno federal puede basarse en su poder para hacer leyes sobre asuntos exteriores, para promulgar leyes nacionales en este ámbito. Esta postura ha brindado frutos para las mujeres desde la perspectiva del derecho positivo, ya que gracias a la suscripción de la Convención sobre la eliminación de todas las formas de discriminación contra la mujer (conocida por sus siglas en inglés, CEDAW), se han dictado importantes leyes para las mujeres, como el Act of Discrimination de 1984, que tiene por fin dar cumplimiento a la no discriminación, y está dirigida explícitamente al igual tratamiento entre los sexos y a la protección contra la discriminación basada en el sexo, el estado marital, el embarazo y el potencial embarazo, abusos sexuales, despido del empleo en base a responsabilidades familiares ${ }^{16}$.

En la vereda opuesta, pese a que en Israel existe una Carta de Derechos que reconoce la igualdad de los sexos y la jurisprudencia de la Corte Suprema ha declarado "que los principios fundamentales de la libertad individual y la igualdad están, de hecho, consagrados, e incluso integran, el sistema legal israelí"17, las mujeres aún no alcanzan una igualdad total con respecto a los hombres en los distintos ámbitos de la vida. Hay una distancia entre lo constitucionalmente declarado y la práctica jurídica.

fundamentales, por cuanto han sido incorporados a través de la práctica constitucional o por mandato derivado de la propia Constitución (piénsese en la recepción de tratados internacionales vía artículo $5^{\circ}$ de la Constitución). Tomamos este concepto de la forma en que lo ha desarrollado la Corte Constitucional colombiana a partir de 1995, que se basa a su vez en la doctrina del Consejo de Estado francés. Confróntese Arango (2004), pp. 79-102.

16 Karpin y O’Connell (2005), pp. 22 y 34.

17 Hirschl y Shachar (2005), p. 210. 
El caso irlandés, por su parte, es un buen ejemplo de sistemas jurídicos en los que los derechos consagrados constitucionalmente se pueden transformar en derechos meramente nominales. La Constitución irlandesa reconoce expresamente "el derecho a la vida del no nacido", incorporado vía referéndum la octava enmienda el año 1983 que establece que: "El estado reconoce el derecho a la vida del no nacido y con la debida consideración del igual derecho a la vida de la madre, garantiza en sus leyes el respeto, y, en la medida de lo posible, mediante sus leyes defiende y vindica este derecho" (art. 40.3.3), ubicando así al derecho irlandés como uno de los más restrictivos a nivel europeo, ya que admite el aborto únicamente en caso de riesgo real e importante para la vida de la madre (incluido el riesgo de suicidio), que no pueda ser evitado salvo por la interrupción del embarazo ${ }^{18}$. En este contexto, un caso emblemático tuvo lugar en el año 1992 a propósito de una orden de arraigo de una adolescente de 14 años embarazada producto de una violación, que pretendía abandonar Irlanda por los 9 meses siguientes. La solicitud fue acogida por la Corte, pese al el voto disidente de Costello, quien basó su opinión en las evidencias médicas que daban cuenta del deterioro de la salud psicológica de la adolescente si se le exigía continuar con su embarazo y que "el daño a su salud mental sería devastador ${ }^{\prime \prime 19}$.

Este caso ilustra el rol que puede desempeñar la jurisdicción constitucional y su voluntad de interpretar la constitución en clave feminista. Ante el impacto del fallo y la presión social, el gobierno costeó una apelación a la Corte Suprema, donde se le dio la razón a la joven, ante "la necesidad de armonizar y sopesar los diferentes principios y derechos contenidos en la Constitución", el art. 40.3.3, dijo el ministro presidente, debería ser leído a la luz del preámbulo de la Constitución "con el énfasis puesto en la interpretación de los derechos en concordancia con los conceptos de prudencia, justicia y caridad". El aborto, concluyó la Corte, se justifica en ciertas circunstancias, como cuando hay un riesgo real y sustancial para la vida de la mujer, incluyendo el riesgo del suicidio ${ }^{20}$.

Lo que queremos destacar es que, tratándose de la Constitución Irlandesa (y de cualquier otra), toda referencia a un derecho a la igualdad entre las personas se vuelve un "derecho de papel" si a renglón seguido se criminaliza el aborto y la judicatura constitucional no muestra un compromiso con una lectura feminista de la misma. Y es que, cuando las constituciones reconocen que el derecho a la vida se extiende al feto sin matices, se contravienen el principio de igualdad de género y representación porque "anula las opciones de vida de la mujeres

\footnotetext{
18 Mena (2012), p. 116.

19 IRVING (2008), p. 202.

20 IRVING (2008), p. 203.
} 
[y no la de los hombres], su dignidad, salud y autonomía, incluyendo la autonomía de sus relaciones personales" 21 . Es decir, no bastan "derechos de papel" que consagren la igualdad de género, para respetarla y promoverla, así como tampoco no es razón para vulnerarla el que no esté consagrada expresamente, tal como sucede en el caso australiano, lo que no quiere decir que resulte absolutamente indiferente que la igualdad de género esté o no consagrada expresamente en la Carta Fundamental, sino que ello es un solo un ingrediente en la receta para alcanzarla.

\section{La interpretación teleológica de la Constitución, una aliada}

Siguiendo a Ruth Rubio-Marín y Beverly Baines, Irving rescata la importancia de la metodología interpretativa y la hermenéutica constitucional con el fin de darle sentido a las normas desde una perspectiva de género. En particular, el criterio teleológico es útil siempre que se utilice para indagar el propósito de una legislación en un nivel de abstracción que pueda adaptarse a nuevas formas de cumplirlo. Conforme a esta aproximación, la otrora Ministra de la Corte Suprema Canadiense, Bertha Wilson, argumenta que la interpretación teleológica debe concebirse como la continuación de la intención misma de los derechos constitucionales y que hay, incluso, más en juego en la interpretación que en los propios derechos constitucionales. La interpretación teleológica debe ubicar a la constitución y la experiencia de quienes son su objeto, en el contexto social. El significado que se extrae de la constitución, mediante este sistema de interpretación, descansa en dos tipos de significados, la intención y la consecuencia. La intención es explorada en la consecuencia, el propósito en el contexto ${ }^{22}$.

Debe tenerse en cuenta que, cuando hablamos de interpretar la constitución desde una perspectiva feminista, utilizando el método teleológico, no pretendemos con ello uniformar las realidades de las mujeres, ya que no abogamos por una postura esencialista y reduccionista, y con ello echar al olvido las diferencias entre ellas provenientes de su realidad social, económica, racial, sexual, entre otras. Sin embargo, creemos que debe buscarse un punto de encuentro entre todas estas diferencias, ya que posturas muy radicales olvidan que la equidad y representación de género son capaces de acomodar la diferencia, mientras que admiten que el reconocimiento político y legal de la diferencia requiere de la agrupación y con ello el reconocimiento de lo común. En efecto, "el contexto cultural, racial, económico y nacional es el lienzo sobre el cual el diseño de

21 IRVING (2008), p. 207.

22 IRVING (2008), pp. 56-62. 
la constitución debe ser elaborado" 23 y, posteriormente, deberá aplicarse en la interpretación de la misma el método que contextualice los conceptos comunes de las mujeres en el marco de sus diferencias.

Para hacer frente a esta falta de pertenencia -o pertenencia a medias- de las mujeres a la comunidad constitucional, es preciso situarnos desde una postura feminista para leer, interpretar y aplicar las constituciones, lo que implica un compromiso con la equidad y representación de género que se traduce en un compromiso por el respeto hacia la igualdad y dignidad de las mujeres (exista o no un texto expreso que las consagre) con el fin de lograr un verdadero sentido de pertenencia. Así entonces, desde esta posición feminista se abrirá espacio para reconceptualizar la historia de las mujeres y darles su lugar en la comunidad constitucional.

Ahora bien, nuestro objetivo en este artículo es contextualizar esta falta de pertenencia de las mujeres a la comunidad constitucional específicamente respecto del ejercicio de sus derechos sexuales y reproductivos y en especial cuando se les prohíbe institucionalmente el acceso a un aborto legal y seguro, examinando el puente (o la ausencia de este) que la jurisprudencia comparada ha trazado entre el derecho al aborto y el derecho constitucional a la igualdad y la dignidad, para luego, desde una perspectiva feminista, construir un argumento fundado en la dignidad humana (desde la perspectiva del enfoque de las capacidades) y el derecho humano a la igualdad para la constitucionalización de los referidos derechos sexuales y reproductivos de las mujeres.

\section{Una aproximación al derecho humano a la igualdad y a la dignidad humana desde el enfoque de las capacidades}

\subsection{Sobre el derecho humano a la igualdad}

Las personas no son iguales y con el paso del tiempo ello no llega a suceder tampoco. Es más, puede ocurrir que las diferencias se acentúen. Aunque resulte contraintuitiva, la afirmación anterior es efectiva. Desde una perspectiva material (real) los seres humanos somos tan diferentes entre sí, como tantos pertenecemos a la especie. La igualdad -como sinónimo de analogía- ${ }^{24}$ entre las personas, se puede predicar cuando las hacemos semejantes o equivalentes

23 IRVING (2008), p. 35.

24 "La analogía implica algún grado de semejanza, de equivalencia, lo que, ciertamente, será predicable solo respecto de ciertos aspectos que se consideran relevantes", y no como igualdad como identidad o semejanza. FigueroA (1996), p. 5. 
bajo ciertos aspectos que se consideran relevantes ${ }^{25}$, es decir: "los juicios de igualdad constatan la igualdad respecto a determinadas propiedades" 26 .

Lo dicho no implica que cada persona debe ser tratada de manera distinta, ya que no es moralmente deseable tener como principio básico el que las personas deban ser tratadas de acuerdo a sus diferencias porque, entonces, a todo ser humano se le debería tratar de una manera especial, exponiéndonos a tratos injustos y vejatorios. Además, desde una perspectiva lógica, no es correcto concluir que por ser las personas diferentes entre sí, estas deban ser tratadas de modo diferente, ya que con ello se incurriría en una falacia naturalista. En este sentido, el mandato del derecho humano a la igualdad prescribe la obligación de tratar a todas las personas con igual consideración y respeto, a pesar de sus diferencias. Este mandato, en cuanto tal, no tiene por propósito definir la realidad, sino prescribir u ordenar cómo deberíamos ocuparnos de ella normativamente ${ }^{27}$.

Cuando se invoca a la igualdad, por lo general se hace echando mano a la vieja regla aristotélica, conforme a la cual "hay que tratar igualmente a los iguales y desigualmente a los desiguales". Sin embargo, si la vamos a invocar, ello debe estar precedido de una serie de salvedades, pues la máxima aristotélica implica un planteamiento más complejo que comprende la igualdad por equiparación y por diferenciación ${ }^{28}$. Además de lo anterior, conviene recordar lo planteado

\footnotetext{
25 Figueroa (1996), p. 5.

26 Alexy (2008), p. 352.

27 La naturaleza normativa del principio de igualdad incluye tres sentidos correlativos, a saber: a) los hechos de la realidad no definen una situación como igualitaria o desigualitaria, sino que es la valoración de los mismos realizada por la sociedad la que le atribuye un significado y determinadas consecuencias normativas que definen su carácter igualitario o no; b) el principio de igualdad es un mandato que tiene como función establecer cómo deben ser tratados los rasgos de la realidad humana y en ningún caso describe su identidad; c) la igualdad es una meta-norma, es decir, una gran directriz del conjunto de normas que regulan la sociedad, de tal importancia que cada una de ellas debe velar porque en su contenido y aplicación no se le vulnere. LAPORTA (1985), pp. 3 y 4 . Lo determinante de su carácter normativo ha quedado de manifiesto, entre otras razones, a propósito de polémicas teorías basadas en investigaciones científicas que han apostado por argüir la superioridad de una determinada raza (negra) y sexo (masculino). Es en virtud de la naturaleza normativa del principio en comento, que podemos sostener la coherencia que existe entre el respeto al principio de igualdad y la posibilidad de aceptar que estas teorías sean veraces, puesto que, dada su naturaleza, ante la pregunta de si acaso " ¿sería defendible el racismo... si suponemos que un grupo étnico resulta efectivamente poseer un cociente intelectual $(\mathrm{Cl})$ medio superior a otro...?", podemos seguir respondiendo de modo negativo, por cuanto "el principio de igualdad no se basa en la igualdad real que todas las personas comparten". SINGER (1995), pp. 34-38, de ahí que la diferencia que exista entre ellas -superioridad intelectual de una raza por sobre otra, por ejemplo-, no obste el respeto a la igualdad de trato que aquél prescribe por las razones normativamente correctas.
}

28 Peces-Barba (1999), p. 243. 
por Alexy ya que nos permite arribar al correcto sentido del principio. Dicho autor ha sostenido que dos juicios de igualdad fáctica parcial como elemento inicial, no aportan nada sobre el deber o no de un trato igualitario o diferenciado, ya que la "igualdad fáctica parcial es conciliable con un trato desigual y la desigualdad fáctica parcial, con un trato igual" 29 . Es decir, no bastan como condición de aplicación de una norma. Por ello, las palabras igual y desigual en la fórmula clásica, no implican una igualdad o desigualdad fáctica. Luego, es preciso que la igualdad y la desigualad sean valorativas, de este modo se contribuye a la fundamentación de tratos diferenciados. Por último, deberá ser "una igualdad relativa a determinados tratos pues, si no lo fuera, no podría explicarse por qué dos personas que, desde cierto punto de vista tienen que ser tratadas igualmente, no lo serán desde todos los demás puntos de vista. [Ambas relativizaciones constituyen las] condiciones para que un trato diferenciado sea posible ${ }^{\prime \prime 30}$. Luego, este último ha de ser el sentido que debe darse a la fórmula clásica, recordando siempre que la exigencia de la igualdad de trato se refiere al contenido de la norma y no a su formulación lógica.

\subsection{Concepciones de la igualdad}

En materia de igualdad de género, la jurisprudencia comparada admite una serie de significados, distinguiéndose al menos dos concepciones: la doctrina de la igualdad formal y la doctrina de la igualdad sustantiva o de resultado. En el caso de la igualdad formal, el sexo de una persona no revela nada acerca del valor individual o de su autonomía; su objeto principal es crear un orden legal neutral desde la perspectiva del género. Sin embargo, los ordenamientos jurídicos en general no son (ni han sido) neutrales desde este punto de vista. Al contrario, principalmente han sido una proyección más del orden social patriarcal jerárquicamente estructurado, cuyos dividendos los reciben mayoritariamente los hombres, no obstante su retórica supuestamente universal, que es ciega a la posición de subordinación y de opresión en la que se encuentran las mujeres.

Un ejemplo de la aplicación de esta doctrina tuvo lugar en la década de los 70 y principios de los 80 en Alemania, a propósito de las diferencias biológicas entre los hombres y las mujeres. Durante este período, la Corte Constitucional Federal buscó la igualdad formal. Para este fin, las "diferencias biológicas y funcionales" estaban estrechamente definidas y el tratamiento diferente entre los sexos era sistemáticamente condenado como discriminatorio ${ }^{31}$. Pero este modelo

\footnotetext{
29 Alexy (2008), p. 352.

30 Alexy (2008), p. 353.

31 Rodríguez y Sacksofsky (2005), pp. 172-173.
} 
resulta demasiado estrecho para revertir y transformar la posición desventajosa de las mujeres, en todo ámbito de sus vidas, ya que ello demanda herramientas que van más allá de la igualdad formal y la discriminación directa.

Un fallo de la Sala Constitucional costarricense ${ }^{32}$ de la década del 90 lo deja en evidencia al rechazar un reclamo de inconstitucionalidad del artículo 104 del Código Laboral que establecía doce horas de trabajo diario para las trabajadoras domésticas, mientras que para los demás trabajos el máximo eran ocho. Al respecto, la Sala afirmó que la norma no introducía "una distinción arbitraria o una desigualdad contraria a la dignidad humana (...) el servicio doméstico es una situación excepcional que no puede ser equiparada a otro caso como es la agricultura, la industria u otros servicios" ${ }^{\prime 33}$. Lo anterior da cuenta de la falta de consideración de la discriminación indirecta que padecen las mujeres, la cual no se verifica por medio de un trato menos favorable que se encuentre explícito en la regla, sino que obedece a una práctica subyacente que impone barreras invisibles a las mujeres para poder subvertir su posición de desventaja. Dada la fuerza que la discriminación indirecta ejerce sobre los grupos menos aventajados de la sociedad (entre los cuales se encuentra el de las mujeres) sometiéndolos a permanecer en su estado de menosprecio, pero, especialmente, dado su carácter subrepticio, se hace indispensable evidenciarla y desafiarla a nivel institucional, de manera tal de librar una lucha contra "el problema de las políticas y reglas que tienen un impacto adverso, in-intencional, desproporcionado e innecesario sobre ciertos grupos" ${ }^{\prime \prime 34}$.

No obstante lo anterior, esta situación solo fue advertida por el voto disidente de la Sala que declaró que "la norma era inconstitucional porque discriminaba a las mujeres como trabajadoras en base al género. Un gran porcentaje de trabajadoras domésticas son mujeres, y la legislación parece estar basada en la percepción cultural del trabajo doméstico sea o no remunerado, como 'trabajo de mujeres', y por tanto devaluado" ${ }^{\prime 35}$.

En Chile, tal como lo señala Figueroa, no solo la doctrina sino también la jurisprudencia se han hecho cargo de la situación jurídica y de hecho que constituye la discriminación indirecta. En efecto, el Tribunal Constitucional ha incorporado este concepto al invocar un informe de la Alta Comisionada de Naciones Unidas que establece que "la discriminación indirecta se produce cuando una ley, una política o un programa que parecen neutros (...) tienen un

32 Corte Suprema de Justicia, Decisión № 3150, de junio 28 de 1994.

33 FACIO et al. (2005), p. 115.

34 SMITH (2011), p. 143.

35 FACIO et al. (2005), p. 116. 
efecto discriminatorio en el momento de su aplicación. En ese caso, el resultado o efecto final provoca una situación de desventaja de la mujer con respecto al hombre, debido a las desigualdades existentes no tratadas por una medida supuestamente neutra" ${ }^{\prime \prime 6}$.

La igualdad sustantiva o de resultado, por su parte, pretende hacer efectivo el mandato de igual trato y consideración, poniendo sobre el tapete la idea de que en muchas ocasiones el sexo debe importar a la hora de dar un trato diferente (preferente) a quienes históricamente han sido social, económica y políticamente vulneradas. En palabras de Iris Marion Young, "la igualdad, definida como la participación e inclusión de todos los grupos en instituciones y posiciones, a veces se ve mejor satisfecha por el trato preferencial (...) [de ahí que] la acción afirmativa ya no necesita ser vista como una excepción al, por lo demás operativo, principio de no discriminación [pasando a ser aquellas] una de las muchas políticas de conciencia de grupo que contribuyen a socavar la opresión" ${ }^{\prime 37}$.

La igualdad sustantiva tiene una vocación trasformadora. Con ella se pretende revertir la posición histórica de subordinación y postergación que han sufrido las mujeres y que el modelo de la igualdad formal no ha sido capaz de corregir y compensar. En efecto, la igualdad sustantiva muestra que la igualdad formal puede producir resultados no equitativos pues los tratamiento similares son ofrecidos a personas que, precisamente, no están en una posición similar $y$, por ende, pueden generar o facilitar nuevas desventajas para la que ya se encuentra en una posición desfavorecida ${ }^{38}$. El único camino por recorrer es, entonces, identificar los patrones de opresión y subordinación de las mujeres como grupo -teniendo presente que la discriminación es un hecho histórico con repercusiones estructurales en la sociedad-y proponer como objetivo central de la igualdad la transformación de los patrones sociales de discriminación ${ }^{39}$.

Así lo ha entendido, al menos parcialmente, la reciente jurisprudencia constitucional colombiana al acoger la doctrina de la igualdad sustantiva y su propósito transformador, para legitimar moral y jurídicamente la aplicación de medidas de acción afirmativa, no solo en materia de representación política, sino también en materia laboral, distinguiendo la edad de jubilación de los hombres y de las mujeres (65 y 60 años, respectivamente). Sobre el particular, la Corte Constitucional ha manifestado que esta ley se justificaba moral y jurídicamente puesto que estaba "diseñada para compensar la continua posición inferior de

\footnotetext{
36 Figueroa (2014), p. 18.

37 Young (2000), p. 329.

38 IRVING (2008), p. 2.

39 Baines y Rubio-Marín (2005), p. 14.
} 
las mujeres en la sociedad (...) debido a su doble jornada como miembro de la fuerza laboral y como responsable del trabajo doméstico (...) El legislador [entonces] podía tomar medidas positivas para corregir desigualdades de facto para compensar (...) y para promover la igualdad real y efectiva de las mujeres en el orden económico y social" ${ }^{\prime 40}$.

La jurisprudencia de la Corte Constitucional de Colombia aplica esta doctrina de la igualdad sustantiva, enfocándose en las consecuencias que en materia de género trae aparejado el artículo 13 de la Constitución que establece que "[e] I Estado promoverá las condiciones para que la igualdad sea real y efectiva y adoptará medidas a favor de grupos discriminados o marginados". Siguiendo este criterio, en 1991, la Corte consideró, conociendo de un caso relacionado con los derechos sociales que asisten a las hijas solteras de oficiales militares, a "la discriminación a favor de las hijas por sobre los hijos, como una medida de hacer 'real y efectivo' el principio de igualdad, dada la dependencia económica frecuente de las mujeres sobre los hombres en la sociedad Colombiana"41.

Con todo, en la búsqueda de revertir la histórica situación desventajosa de las mujeres, la Corte ha adoptado decisiones que perpetúan la visión de las mujeres como dependientes económicamente y destinadas preferentemente a las labores domésticas. No obstante su propósito loable, y que en muchas ocasiones los resultados han sido en su mayoría buenos para las mujeres, se debe tener presente que este efecto a largo plazo puede ser pernicioso, ya que la idea final debe ser la de contribuir a cambiar la estructura social del género y no perpetuarla. Por ello, cobrarán suma importancia los argumentos jurídicos que justifiquen cada una de estas decisiones, ya que otorgar beneficios que tienden a mantener el statu quo será, en el largo plazo, contraproducente. En este sentido, la Corte Constitucional ha intentado esquivar estos potenciales efectos perniciosos, y en ese contexto, rechazó un intento basado en el artículo 13 de la Constitución que permite la discriminación positiva, para "conservar la posición de las cuidadoras de casa como exclusivamente para mujeres (...) Respecto de ello la Corte sostuvo que los hombres pueden desarrollar trabajos tan bien como las mujeres, y la exclusión de ellos implica contribuir a perpetuar perjuicios, ignorando la igualdad esencial de todos los seres humanos" ${ }^{\prime \prime 2}$.

La aplicación práctica de la igualdad de resultado se ve reflejada generalmente en tratamientos diferenciados respecto de situaciones que, no obstante ser semejantes, se les distingue en razón de un elemento que las diferencia y que bajo ciertas circunstancias cobra importancia. En efecto, si bien la igualdad

\footnotetext{
40 Morgan (2005), p. 88.

41 Morgan (2005), p. 87.

42 Morgan (2005), p. 88.
} 
formal nos obliga a cancelar "ciertos rasgos distintivos como razones relevantes para diferenciar en el tratamiento normativo" 43 , la igualdad sustantiva exige que bajo determinadas circunstancias esas diferencias (sexo, raza, capacidad diferente, etc.) cobren importancia, redundando en un tratamiento diferenciado ${ }^{44}$. La Corte india, acogiéndose a la teoría de la igualdad sustantiva, ha aprobado la implementación y aplicación de las medidas de acción afirmativa, no obstante que la igualdad sustantiva no se encuentra definida en la Constitución ${ }^{45}$. Sin embargo esta Corte ha incurrido en un error al tratar a las medidas de acción afirmativa como una excepción al principio de igualdad, debilitando así la jurisprudencia elaborada al respecto. Y es que, cuando se aplica un tratamiento diferenciado mediante una acción de discriminación inversa, no estamos frente a un caso de excepción al principio de igualdad sino que la aplicación de éste en su dimensión diferenciadora ${ }^{46}$.

Helen Irving, al referirse a las medidas de acción afirmativa a favor de una determinada raza, profundiza nuestro argumento al plantear que "la acción afirmativa (...) no es un límite para el principio de igualdad racial. Ellas son una medida afirmativa para darle efecto o contenido (...) Tal como la igualdad racial, las leyes afirmativas o los programas diseñados para lograr la igualdad de género, o para mitigar las desventajas basadas en el género, no son derogaciones del principio de igualdad, sino que ellas son la forma de darle efecto" ${ }^{47}$.

Por otra parte, existen casos como el de Israel en que, pese a que el principio constitucional de igualdad abre paso a los tratamientos diferenciados a favor de las acciones afirmativas de género, la jurisprudencia ha preferido optar por favorecer la doctrina de la igualdad formal (sameness). En efecto, en 1998 la Suprema Corte se pronunció acerca de una enmienda legislativa del año 95 de la Ley de Servicio Civil, que introducía la acción afirmativa para las mujeres en los servicios civiles imponiendo la obligación a los Comisionados del Servicio Civil para que promovieran la adecuada representación de las mujeres en los rankings de seniors del Servicio Civil. En este contexto legislativo se solicitó a la Corte que ordenara a todas las agencias de gobierno que ejecutaran la obli-

${ }^{43}$ LAPORTA (1985), p. 14.

${ }^{44}$ Este tratamiento diferenciado puede llevarse a la práctica mediante las denominadas acciones positivas entre las que se destaca un especie particularmente severa, pero sin ser identificadas por completo con ellas: la discriminación inversa o positiva, entendida como una estrategia a favor de un grupo social determinado generalmente por su sexo, etnia o discapacidad, con el fin de eliminar una discriminación anterior o compensar las desventajas crónicas que padecen los miembros de ese grupo. Ruiz Miguel (1996), p. 125 y Puyol (2010), p. 89.

45 Nussbaum (2005), pp. 179-180.

46 Figueroa (1996), p. 30.

47 IRVING (2008), p. 180. 
gación a través de medidas de tratamiento diferente, para lograr un adecuado estándar de representación, ante lo cual la Corte, limitando el mencionado estándar, declaró que no implicaba necesariamente que una mujer candidata seria elegida cuando los candidatos poseen similares calificaciones. Es decir, solo aseguraba una igualdad de oportunidades, mas no una igualdad de resultados. Por tanto, conforme con el criterio de la Corte Suprema, el principio de igualdad, permite el tratamiento diferente, pero no establece una obligación de promover o contratar miembros de un grupo infrarrepresentado ${ }^{48}$.

En Chile, por su parte, el Instituto Nacional de Derechos Humanos, en el reconocimiento del carácter transformador de la doctrina de la igualdad sustantiva, con miras a alcanzar la igualdad material, ha manifestado que el Estado tiene la obligación de garantizarla ${ }^{49}$. Lo anterior, en caso alguno podría objetarse desde una perspectiva constitucional ya que si bien nuestra Carta Fundamental no se compromete con ninguna doctrina de igualdad en particular, o con ningún modelo de igualdad como prefiere Ilamarlos Figueroa, tampoco "excluye ni prohíbe, en forma expresa o implícita, ningún modelo de igualdad" ${ }^{\prime 50}$. En este sentido, siguiendo siempre a Figueroa, la jurisprudencia constitucional chilena ha sido congruente con las dos afirmaciones anteriores (la obligación del Estado de garantizar la igualdad sustantiva y la falta de prohibición o exclusión de la misma a nivel constitucional). En efecto, "la Corte Suprema ${ }^{51}$ chilena ha establecido que el principio de igualdad contenido en la Constitución no puede entenderse en forma rígida y dogmática, por lo que la ley puede hacer diferenciaciones entre personas o grupos que no impliquen discriminaciones arbitrarias o supongan diferencias o privilegios que deterioren o destruyen esa igualdad. Y concluye 'la discriminación positiva, establece que las normas impugnadas no son inconstitucionales porque su objetivo es (...) la protección de cierta categoría de personas para resguardar su debilidad social, cultural y económica frente a otros estamentos de la sociedad chilena que no se encuentran en las mismas condiciones, como lo son los indígenas del país'"152.

\footnotetext{
48 HIRSCHL y SHACHAR (2005), pp. 215-216. ¿Qué valor tiene que una norma constitucional permita el tratamiento diferente, si a la vez no obliga a implementarlo cuando la ocasión lo requiera? Si una norma constitucional permite la aplicación de un tratamiento diferente es porque ella se representa ciertas hipótesis en las que correspondería hacerlo. Ahora bien, cuando esto ocurre, cuando establecemos que el tratamiento diferenciado se permite, por cuanto es necesario ¿por qué no establecer su obligatoriedad?, ¿qué sentido lógico tiene decir "sí, se puede en tal o cual caso y por tales o cuales razones" y luego dejar la puerta abierta para que ello no suceda?

${ }^{49}$ Figueroa (2014), p. 6.

50 Figueroa (2014), p. 4.

51 Corte Suprema, rol № 17.058-1993, de 25 de junio de 1993.

52 Valenzuela y ZúNíga Fajuri (2013), p. 14.
} 


\subsection{Sobre la dignidad humana desde la perspectiva del enfoque de las capacidades}

El enfoque de las capacidades es una herramienta elaborada por Amartya Sen y Martha Nussbaum para poder medir la calidad de vida de las personas y poder teorizar de este modo acerca de la justicia social en un país o región determinada. Sin embargo Nussbaum, en el desarrollo de la misma, se ha apartado de Sen quien se ha centrado en el rol de las capacidades en la demarcación del espacio dentro del cual se hacen las valoraciones de la calidad de vida, mientras que ella utiliza la idea de manera más exigente, como base para principios políticos básicos que deberían suscribir garantías constitucionales ${ }^{53}$. Esta herramienta resulta interesante a partir de la adaptación que de ella ha hecho Nussbaum, quien, de conformidad con o anterior, la ha desarrollado en una versión en que "estas ideas son usadas como pilares principales de una teoría mínima de la justicia social, en combinación con una idea de la dignidad humana. La idea es que una justicia social mínima es la que asegura a todos los ciudadanos un umbral límite de una lista de derechos claves, sobre la base de que tales derechos son requisitos de una vida merecedora de dignidad humana" ${ }^{\prime \prime 4}$ y que tienen por objeto algo más que la mera supervivencia humana: la prosperidad de la misma, y sin las cuales no consideraríamos una vida totalmente humana ${ }^{55}$. En este sentido, Nussbaum plantea este enfoque como correctamente situado en relación con los problemas que las mujeres enfrentan actualmente, por cuanto nos impone revisar sus vidas en sus escenarios materiales y sociales, de ahí que lo formule como una herramienta que efectivamente pueda cooperar en resolver sus dificultades ${ }^{56}$.

Esta herramienta supone que las personas tengan un umbral de derechos específico para poder hablar de una justicia social mínima. Luego, estos derechos se detectarán respondiendo a la siguiente pregunta: ¿Qué característica realizada propiamente por los seres humanos son tan fundamentales que ellas parecen definitivas de una vida que es verdaderamente humana? En otras palabras, ¿cuáles son las funciones sin las que nosotros consideraríamos una vida como no, o no totalmente, humana ${ }^{27}$ Lo que se pretende es contar con una lista de capacidades -las que a juicio de la autora pueden llegar a contar con el consenso transcultural- que hacen a la persona que los detenta mere-

\footnotetext{
53 Nussbaum (2000), p. 70.

54 Dixon y Nussbaum (2012), p. 68.

55 HAY (2013), p. 33.

56 Nussbaum (2000).

57 HaY (2013), p. 32.
} 
cedoras de dignidad humana, además de acotar el contenido de esta última, ya que de otro modo se podría caer en un uso argumentativo caprichoso e inconsistente. Dentro de las peculiaridades de esta lista de capacidades está su semejanza -no identidad-con los bienes primarios que Rawls desarrolla en Teoría de la Justicia, en el sentido de que se presentan en un espíritu políticoliberal similar, ya que puede ser respaldada para propósitos políticos, como las bases morales de garantías constitucionales centrales, por personas que por lo demás tengan visiones bastante diferentes de lo que la buena vida debería ser para un ser humano. El otro punto en que se asemeja esta lista de capacidades con la teoría de Rawls -bajo el supuesto de que el enfoque de las capacidades en ningún caso pretende ni es una teoría de la justicia- es que desempeñan un rol similar a los referidos bienes primarios, ya que son actrices principales en la elaboración de cualquier alternativa de vida posible, de manera que tienen una demanda especial de ser apoyadas para propósitos políticos en una sociedad pluralista. Así, el listado de capacidades que Martha Nussbaum enuncia en su libro Women and Human Development: The Capabilities Approach, se compone de las siguientes: la vida, la salud corporal, la integridad corporal, los sentidos, la imaginación y los pensamientos (estos tres últimos como un solo ítem), las emociones, la razón práctica, la afiliación (en relación a otros seres humanos), el relacionarse con otras especies del reino animal, natural y vegetal, el jugar y el control material y político sobre el entorno ${ }^{58}$.

Es preciso tener en cuenta el carácter independiente de estas capacidades. En palabras de Nussbaum, son separate components (componentes separados), de manera tal que no se puede pretender que con la satisfacción de una de ellas se realice otra diferente pues cada una tiene una importancia crucial y se distinguen en calidad (quality). Dada su pluralidad irreductible, se restringe la compensación y la aplicación del análisis costo-beneficio de que pudiesen ser objeto. No obstante lo anterior, las capacidades enlistadas están inexorablemente relacionadas unas con otras de maneras muy complejas. En efecto, ello se evidencia al reflexionar en torno a lo siguiente: una "de las formas más efectivas para promover el control de las mujeres sobre su entorno, y su efectivo derecho de participación política, es promover su alfabetización. Las mujeres que pueden buscar empleo afuera de su hogar tienen opciones de salida que les ayudan a proteger su integridad corporal de violaciones dentro de ellos. La salud reproductiva está relacionada de muchas maneras complejas con la razón práctica y la integridad corporal. Esto nos da aún más razones para evitar promover una a expensas de las otras ${ }^{\prime \prime 59}$.

58 Nussbaum (2000).

59 Nussbaum (2000), p. 81. 
Luego, el Estado será quien deberá asegurar la lista de "capacidades humanas" u oportunidades a que nos referimos ${ }^{60}$. Además, la dignidad y su protección implica la protección en el ámbito de decidir, la salud mental y corporal en todos los contextos, no solo en una situación en que la intromisión es igual para todos ${ }^{61}$. Esta obligación del Estado de asegurar las capacidades humanas, cobra sentido y materialidad cuando nos representamos el tema del aborto, tal como lo dejamos entrever en el párrafo anterior. En efecto, la existencia de una legislación que tenga en mente el reconocimiento y promoción de los derechos sexuales y reproductivos de las mujeres, junto con los planes de salud pública y de educación sexual gestionados a nivel estatal, resultan determinantes para el bienestar integral de las mujeres, y, en caso de ausencia de estos, para la perpetuación de las violaciones en contra de su vida, salud, igualdad, dignidad, etc. Lo anterior por cuanto "donde se concentran las restricciones legales más severas (...) las cifras de aborto son más abultadas; mientras que la tasa de abortos desciende, de manera significativa, en aquellos países donde la legislación es más permisiva e involucra, además, la cobertura sanitaria pública para la interrupción del embarazo (... ${ }^{62}$. Los abortos clandestinos [por tanto,] generan un grave problema de salud pública, debido a la frecuencia de complicaciones físicas y el consiguiente incremento de las cifras de mortalidad materna; daños a la salud psicológica de las mujeres y colisiones entre los deberes de denuncia y el secreto médico que afectan al personal de salud"63.

De todo lo dicho, es indudable que la proclama kantiana de observar a la persona como un fin en sí mismo y no como un medio se deja ver, sin embargo, pese a que la idea kantiana de la dignidad es en parte recogida por el enfoque de las capacidades, pues considera a cada persona como portadora de valor, es decir, como un fin en sí mismo, preferimos este último ya que tiene ventajas relevantes. Primero, Kant establece que la dignidad humana deriva únicamente de la racionalidad, mientras que el enfoque de las capacidades entiende las bases de la dignidad humana de manera más integradora: la dignidad humana es inherente a la sensibilidad, emoción, afectos, salud física y el apetito, así como también a la racionalidad. En segundo lugar, Kant supone que la dignidad humana es inmune a cualquier contingencia o accidente natural, en cambio el enfoque de las capacidades concibe a la dignidad como vulnerable. Desde la perspectiva del enfoque de las capacidades, las privaciones de las oportunida-

60 Dixon y Nussbaum (2012), p. 68-69.

61 Dixon y Nussbaum (2012), p. 79.

62 La penalización del aborto "solo discrimina a las mujeres sin recursos, pues donde el aborto es legal el riesgo de muerte es menor de 1 por cada 500.000 mujeres". ZúñIGa Fajurı (2011), p. 165.

63 ZúÑiga AÑaZCo (2013), p. 267. 
des de salud o bienestar emocional son tan pertinentes para el concepto de la dignidad humana como las privaciones de la libertad de decisión ${ }^{64}$.

\section{Buscando un(os) fundamento(s) para el derecho al aborto. Hacia la constitucionalización de los derechos sexuales y reproductivos de las mujeres}

Para Stuart Mill, la opresión es una negación de la igual libertad, equivalente a una negación de la oportunidad de desarrollar las capacidades racionales de una persona para pensar y actuar. Siguiendo esta idea, y conforme a los requisitos que Carol Hay establece para ser un individuo oprimido, las mujeres calzan en dicha categoría, por cuanto son injustamente perjudicadas en razón de su pertenencia a un grupo específico, el de las mujeres, y este perjuicio es parte de una red estructural y sistémica de instituciones sociales. Además de ello, cumplen con ser un grupo que carece de estima social, poder y autoridad y el perjuicio es injusto, inmerecido o ilegítimo en algún sentido ${ }^{65}$.

Si pensamos la libertad que tienen las mujeres para ejercer sus derechos sexuales y reproductivos en clave kantiana, tenemos que decir que se vulnera el imperativo categórico que ordena que debemos utilizar nuestra humanidad (nuestra naturaleza racional que es nuestra capacidad para establecer y perseguir fines a través de la razón) ya sea respecto de uno mismo o de cualquier otra persona, siempre como un fin, nunca simplemente como un medio. En efecto, cuando se aprueba una norma que criminaliza el aborto y/o cuando se reproduce esta norma en la jurisprudencia constitucional, confirmándola y sosteniendo que ella no vulnera la igualdad y la dignidad de las mujeres, quienes están legislando o llevando a cabo la judicatura, están vulnerando el referido imperativo categórico por cuanto están utilizando las capacidades reproductivas de las mujeres, en ausencia de sus voluntades, como un medio para perpetuar estereotipos de género que los benefician. No están pensando en ellas como seres valiosos en sí mismos, sino que dicho valor se lo atribuyen a lo que obtienen con ellas al gobernar sus cuerpos. Cuando uno comprende a otro ser humano como medio, lo que está haciendo respecto de él o ella es cosificarlo $^{66}$.

64 Dixon y Nussbaum (2012), p. 68.

65 HaY (2013), pp. 3 y 4.

${ }^{66}$ En el caso de las mujeres, la cosificación o reificación sexual que las afecta, va desde el acoso sexual callejero más burdo hasta la obligación institucional de cumplir ciertos roles de género que implican, entre otras funciones, el de llevar adelante, a toda costa, la maternidad. Esta deshumanización, plantea Linda LeMoncheck, "degrada el igual estatus moral de las mujeres, lo que deriva en ser tratadas como si ellas tuviesen menos derecho al bienestar y a la libertad que los hombres que las cosifican. Cuando las mujeres son vistas como si su función principal fuera la gratificación sexual de los hombres [o la 
Dado el contexto opresivo en que las mujeres viven, en muchas ocasiones son ellas mismas las que atentan contra su propia humanidad (en clave kantiana) y dignidad (desde la postura del enfoque de las capacidades), es decir, faltan al deber del auto-respeto, expresando la creencia de que no se es moralmente equivalente a los otros, atentando contra su naturaleza racional y su capacidad para establecer y perseguir fines a través de la razón. El auto-respeto, según lo plantea Robin Dillon "es un elemento constitutivo de muchas de nuestras características morales más importantes (...) la personalidad, los derechos, la agencia, la autonomía, la integridad, la responsabilidad, la identidad, el carácter ${ }^{\prime \prime 67}$. Con el tiempo, esta falta de autoestima, permite conservar el statu quo opresivo, ya que el patriarcado causa a muchas mujeres el deseo de satisfacer los roles sexuales estereotípicos que, efectivamente, restringen severamente el tipo de decisiones que están abiertas a ellas. Este fenómeno que ocurre cuando las personas empiezan a tener preferencias que son contrarias a sus mejores intereses debido a los efectos de las fuerzas sociales opresivas, se conoce como el problema de las preferencias adaptativas" ${ }^{\prime 68}$.

Si aplicamos la relación entre opresión y falta de auto-respeto al ejercicio de la sexualidad y las capacidades reproductivas de las mujeres, podemos observar que en muchas ocasiones ellas toman decisiones que van en contra de su propia voluntad. Por ejemplo, nos encontramos con el caso de mujeres que no quieren llevar a término un embarazo y aun cuando tienen la posibilidad legal de interrumpir el embarazo, la desechan por motivos religiosos y/o morales que han incorporado durante la crianza y que cultivan en su adultez, los cuales replican la figura de la mujer como reproductora de la especie. Vivir con la experiencia de haberse practicado un aborto no cabe como una alternativa para estas mujeres, por tanto, dicha opción no existe al momento de sopesar su decisión. Los roles de género impuestos institucionalmente son los que dirigen las decisiones de muchas mujeres cuando se trata del ejercicio de su sexualidad. Y tal como lo plantea Beauvoir, "los roles de género de las mujeres, socialmente prescritos, les ofrecen muy pocas oportunidades para tomar decisiones existencialmente auténticas. Cuando las mujeres toman el rol de una esposa o una madre, sus vidas se vuelven completamente definidas por sus relaciones con sus maridos o sus hijos. En efecto, las mujeres pierden su sentido del yo, ellas se vuelven un 'Otro'"169.

reproducción de la especie], los propios objetivos, intereses y preferencias de las mujeres, son inevitablemente considerados menos importantes que los de sus cosificadores". HAY (2013), p. 94.

${ }^{67} \mathrm{H}_{\mathrm{AY}}(2013)$, p. 71.

${ }^{68}$ HaY (2013), p. 9.

${ }^{69}$ HaY (2013), p. 119. 
Cuando se les dificulta o impide a las mujeres el ejercicio de sus derechos sexuales y reproductivos no se les trata igual que a los hombres pues se les imposibilita desenvolverse como agentes morales que pueden adoptar las decisiones que estimen convenientes para vivir una vida digna, entre las cuales se cuenta el control sobre el propio cuerpo ${ }^{70}$.

\subsection{Manifestaciones del tratamiento desigual perjudicial}

Con esta falta de consideración y respeto se enfrentan muchas mujeres que pretenden ejercer sus derechos sexuales y reproductivos. Se ven limitadas incluso por restricciones establecidas constitucionalmente. Por ejemplo, a propósito del ejercicio de la sexualidad y capacidad reproductiva de las mujeres privadas de libertad, en 1993 en Colombia, se presentó un caso sobre una regulación aplicable a estas mujeres, que les imponía la utilización de un dispositivo intrauterino o pastillas anticonceptivas como condición de las visitas conyugales, exigencia que no se les aplicaba a los hombres en igual situación. La Corte Constitucional colombiana, al conocer de una tutela interpuesta contra la norma en comento, concedió una orden contra su aplicación, y argumentó que "el tratamiento desigual de las mujeres prisioneras constituye una discriminación de sexo en violación del artículo 13, viola los derechos reproductivos y familiares dispuestos en el artículo 42 y 43 [todos] de la Constitución, así como también, disposiciones similares de documentos internacionales de derechos humanos incorporados a la Constitución" ${ }^{\prime 71}$. No obstante lo anterior, la Corte Constitucional colombiana no siempre se ha pronunciado en esta línea, pues ha fallado también en un sentido en que ha denigrado la posición de las mujeres en el ejercicio de su sexualidad y el control de sus cuerpos, diluyéndose la dignidad y la capacidad para desarrollar su agencia moral en igualdad que los hombres frente a las moralidades de los jueces, tal como lo acusaron los propios ministros de la Corte en $1997^{72}$ en un voto disidente, al manifestar que la ley que penalizaba el aborto "violaba la Constitución, al imponer penas criminales (...) para las mujeres que se embarazaban a causa de una violación o por inseminación artificial involuntaria. [Y que, mediante ella] la mayoría pretendía imponer su propia moral y sus prejuicios religiosos, [etiquetando] su retórica como sexista y patriarcal"73.

\footnotetext{
70 FACIO et al. (2005), p. 118.

71 Morgan (2005), p. 94.

${ }^{72}$ Corte constitucional, C-013/97, 23 de enero de 1997. Puede revisarse el fallo aquí: http://www. corteconstitucional.gov.co/relatoria/1997/C-013-97.htm [visitado el 15/07/2014].

73 Morgan (2005), p. 96.
} 
A propósito de este conflicto de intereses, siguiendo al enfoque de las capacidades, es posible conceder legitimidad activa al feto, el cual, pese a no tener mucho camino como agente moral, parece tener incluso una demanda mayor de reconocimiento de su dignidad que una persona vegetativa (a quien el enfoque de las capacidades le reconoce igual dignidad humana que cualquier otra persona con sus capacidades cognitivas desarrolladas). Este enfoque "reconoce que el feto posee un tipo de dignidad humana aunque su dependencia y estatus simplemente potencial significa que su tipo de dignidad es distinta, y no comparable directamente con la de los seres humanos independientes. [De conformidad con lo anterior, la balanza no puede inclinarse siempre a favor de él, ya que] previo a la viabilidad, la existencia continuada del feto como un ser titular de dignidad humana es totalmente contingente de la provisión de apoyo afirmativo de una mujer. [Luego,]... no puede decirse que el feto tiene 'derecho a la vida' a menos que, desde una perspectiva normativa, una mujer esté también bajo una obligación correspondiente de disponer tal apoyo afirmativo, [lo que sería difícil de establecer en una] sociedad liberal que estime la autonomía individual [ya que serán muy pocas las] circunstancias en que sería legítimo - desde la perspectiva de las nociones de justicia- establecer tal deber ${ }^{\prime \prime 7}$.

Por su parte, en 1993, estando vigente la Ley de asistencia para las mujeres embarazadas y la familia en Alemania, la Corte Constitucional Federal reafirmó el derecho a la vida del feto. A su juicio, "el Estado no podía aprobar constitucionalmente el aborto, y si los legisladores descriminalizan el aborto, de todas formas, 'ellos no podían hacer de éste algo legal, a menos que hubiesen aspectos objetivos para considerarlo como una carga irracional para las mujeres. Las cargas normales del embarazo no justificaban el aborto' (... $)^{\prime 75}$. En ocasiones, además, el objetivo de velar por los intereses del feto ni siquiera aparece claramente. Así lo planteó el ministro Blackmun de la Corte Suprema de Estados Unidos, en su voto particular de Planned Parenthood v. Casey $^{76}$, al afirmar que las restricciones al aborto ofendían la garantía constitucional de la igualdad, así como también la de la privacidad, agregó que estas "no proceden exclusivamente del deseo de proteger al no nacido; ellas reflejan y refuerzan los prejuicios acerca del rol de las mujeres" ${ }^{\prime 77}$.

A propósito del estatuto jurídico que le asiste al embrión, cabe mencionar el fallo de diciembre de 2012 de la Corte Interamericana de Derechos Huma-

74 Dixon y Nussbaum (2012), p. 70.

75 Rodríguez y SACKSOFSKy (2005), p. 172.

${ }^{76}$ Corte Suprema, 505 U.S. 833, 29 de junio de 1992. Puede consultarse el fallo aquí: http://caselaw. lp. findlaw.com/scripts/getcase.pl?court=US\&vol=505\&invol=833 [visitado el 2/07/2014].

77 Siegel (2005), p. 328. 
nos en Artavia Murillo y otros (Fertilización in Vitro) vs. Costa Rica ${ }^{78}$, donde se precisó el sentido del artículo 4.1 de la Convención Americana de Derechos Humanos, "en lo relativo al estatuto jurídico del embrión. Así, [estableció] (...) -ratificando de paso, la opinión de la Comisión Interamericana en el asunto "Baby Boy"79 (Informe 23/81)- que, de acuerdo a la interpretación histórica y sistemática de los antecedentes existentes en el sistema interamericano, no es procedente otorgar el estatus de persona al embrión (...) [E]l mencionado art. 4.1 establece que 'toda persona tiene derecho a que se respete su vida' y que 'este derecho estará protegido por la ley y, en general, a partir del momento de la concepción' (...) [L]a fórmula 'en general'(...) permite -en opinión de la Corte- inferir excepciones a la protección que la propia disposición dispensa y que se traducen en la posibilidad de establecer un sistema gradual e incremental de tutela de la vida, en atención a su desarrollo"80.

Por su parte en Chile, el Tribunal Constitucional ${ }^{81}$ al pronunciarse en el año 2008 acerca de la constitucionalidad del decreto supremo reglamentario $\mathrm{N}^{\circ} 48$, del Ministerio de Salud de 2007, que establece las "Normas Nacionales sobre Regulación de la Fertilidad" y donde se autoriza la píldora del día después, manifestó que el nasciturus "es persona desde la concepción [de manera que] (...) el aborto es siempre inconstitucional, sin hacerse ninguna otra pregunta ni detenerse en ninguna otra consideración" ${ }^{\prime 2}$, desconectando de manera absoluta, cualquier argumento relacionado con los derechos de la mujer. Con fallos como el anterior, o dictámenes como el de la Contraloría General de la República ${ }^{83}$, donde declara que "el no nato debe ser considerado como persona" ${ }^{84}$, no nos deben sorprender frases como las esgrimidas por la parlementaria Ena Von Baer (del partido Unión Demócrata Independiente) en marzo de 2012, donde señala que la mujer "solo presta el cuerpo" 85 durante el embarazo, fundando así su

\footnotetext{
${ }_{78}$ Puede consultarse el fallo aquí: http://www.corteidh.or.cr/docs/casos/articulos/seriec_257_esp. pdf [visitado el 12/07/2014].

79 Comisión Interamericana de Derechos Humanos, caso 2141 № 23/81, 6 de marzo de 1981. Puede consultarse el fallo aquí: http://www.cidh.org/annualrep/80.81sp/estadosunidos2141.htm [visitado el 14/07/2014].

80 ZúÑIGa AÑAZCO (2013), p. 265.

81 Tribunal Constitucional, rol № 740-07-CDS, de 18 de abril de 2008.

82 Figueroa (2013), p. 108.

${ }^{83}$ Contraloría General de la República, dictamen № 25.403, de 21 de agosto de 1995.

${ }^{84}$ OsSAndón (2012), p 355.

85 "La mujer, podría decirlo en fácil, le presta el hogar, por el tiempo del embarazo, a la vida que se está gestando ahí. Y esa vida tenemos que respetarla siempre, desde el momento que existe (...) no tiene derecho (a aborto terapéutico) una mujer que presta el cuerpo en el fondo, presta el hogar a esa vida que se va a desarrollar, a terminar con esa vida". http://www.emol.com/noticias/nacional/2012/03/14/530766/
} 
rechazo a las iniciativas legales que buscaban despenalizar la interrupción del embarazo $^{86}$.

Por otra parte, la fragilidad de la igualdad formal, reluce de especial manera cuando hablamos de las diferencias reproductivas. Ya en 1974, dicha fragilidad quedó de manifiesto en el caso Geduldig v. Aiello ${ }^{87}$, cuando la Corte Suprema estadounidense confirmó un programa de seguro para los trabajadores inhabilitados que cubría el sueldo perdido del trabajador con ocasión de procedimientos médicos, pero excluía los ocurridos durante un embarazo normal. Al respecto, la Corte sostuvo que la discriminación de género no está implicada en la exclusión del embarazo porque la distinción hecha por la ley no era entre hombres y mujeres, sino simplemente entre personas embarazadas y no embarazadas; se aplicaba igualmente a hombres y mujeres. Por ello, dicha política estatal no debía someterse a un escrutinio estricto bajo la cláusula de igual protección. Como consecuencia práctica del asunto, tal razonamiento libera a cada estado del escrutinio estricto de la igual protección al regular la conducta de las mujeres embarazadas en materia de aborto y licencias de maternidad ${ }^{88}$. Lamentablemente, aun cuando la Corte reconoció que las mujeres estaban sobrecargadas a propósito del embarazo, atribuyó ello a la biología, desligando al Estado ya que la igualdad formal no les exigía compensar esa diferencia ${ }^{89}$. No obstante la aplicación poco feliz del principio de igualdad, resulta interesante lo que sostuvo el ministro William Brennan, en su voto disidente, al decir que "la igual protección de la ley" garantizada bajo la decimocuarta enmienda debe reconocer "características físicas inexorablemente relacionadas a un sexo"$^{\prime 90}$. Su perspectiva es útil, ya que rescata la diferencia y la sitúa en el contexto real de cada sexo, lo que obliga a reflexionar en torno a las necesidades e intereses que surgen a propósito de las mismas.

En Turquía, a juicio de la Corte Constitucional, la cláusula formal de la igualdad contenida en el artículo 10 de la Constitución impone el tratamiento igualitario respecto de aquellos que están en un estatus legal de igualdad y permite, por tanto, un tratamiento diferenciado respecto de los que no lo están. En cuanto a la igualdad de género propiamente tal, si bien la Corte ha

senadora-von-baer-sobre-aborto-terapeutico-la-mujer-no-tiene-derecho-porque-presta-el-cuerpo.html [visitado el 14/07/2014].

${ }^{86}$ Sobre la titularidad del derecho a la vida del nasciturus, véase FiguerOA (2007).

${ }^{87}$ Corte Suprema, 417 US-484, de 17 de junio de 1974. Puede consultarse el fallo aquí: http://supreme. justia.com/cases/federal/us/417/484/case.html [visitado el 14/07/2014].

88 Siegel (2005), p. 320.

89 Hendricks (2012), p. 264.

${ }^{90}$ IRVING (2008), p. 192. 
manifestado que está contenida en el referido artículo 10, y que "si las diferencias biológicas y funcionales crean una conducta diferente o un privilegio para algunas partes, tal interpretación no es constitucionalmente aceptada (...) muchas de las decisiones de la Corte (...) basadas en la igualdad de género, interpretan este principio de un modo que limita los derechos de las mujeres, más que los asegura"191.

Ahora bien, el trabajo de echar mano al derecho humano a la igualdad no acaba, como dice Irving, con observar solo las protecciones sustantivas "desiguales" cuando se trata de la capacidad reproductiva de las mujeres, sino que además se debe invocar un "reconocimiento especial y disposiciones especiales que estén relacionadas con lograr la igualdad con los hombres per se... ${ }^{192}$. Es decir, debe existir un reconocimiento, como el que invocó el juez Brennan en Geduldig v. Aiello, de las características relacionadas inexorablemente a un sexo. Este reconocimiento implica el de una vulnerabilidad particular y de necesidades particulares de la mujer cuando está embarazada, durante el nacimiento del hijo, cuando cuida a los bebés y a los niños menores. De este reconocimiento ha hecho eco la Constitución colombiana en el inciso final de su artículo $13^{93}$, el cual ha sido productivo desde la perspectiva de los intereses de las mujeres, ya que ha sustentado la decisión judicial de que las mujeres no pueden ser despedidas de sus trabajos sin causa durante su embarazo o durante los tres primeros meses luego de haber dado a luz ${ }^{94}$.

Luego, esta idea acerca del reconocimiento de las propiedades biológicoreproductivas de las mujeres y todo lo que las rodea nos va acercando a nuestra propuesta, ya que no existiría mayor reconocimiento en una nación que la constitucionalización de los derechos sexuales y reproductivos de las mujeres. Pero para arribar a esa conclusión, debemos primeramente aclarar ciertos aspectos vinculados a los argumentos morales y jurídicos en los que se funda dicha constitucionalización. Sin duda, el reconocimiento de algo, ya sea de una cosa, un estado, una situación, etc. exige de su conocimiento previo, para que su identificación sea posible. Luego, cómo identificar algo que ha sido invisibilizado desde siempre, que ni siquiera tiene asignado un nombre. ¿Cómo puedo llegar a reconocer que $X$ necesita de la protección $Q$, si no se me ha representado jamás $\mathrm{X}$, si no la conozco, ¿cómo reconocerla?

\footnotetext{
91 Elver (2005), p. 284.

92 IRVING (2008), p. 193.

93 "El Estado protegerá especialmente a aquellas personas que por su condición económica, física o mental, se encuentren en circunstancia de debilidad manifiesta y sancionará los abusos o maltratos que contra ellas se cometan". Constitución de Colombia, de 1991.

94 IRVING (2008), p. 194.
} 


\subsection{Multiplicidad de argumentos superpuestos}

En medio de la lucha que han dado las mujeres por el reconocimiento y respeto de sus derechos sexuales y reproductivos en general, tanto requirentes como miembros de la judicatura, se han enfrentado a la falta de conceptos asociados a esta materia, cuestión que responde a la invisibilización global de las necesidades, intereses, requerimientos y derechos de las mujeres. Esta falta de conceptualización en materia de capacidades reproductivas y sexuales, sumada a la exigencia de contar con un derecho expresamente consagrado para poder cristalizar los intereses de las mujeres, se ha convertido en una cárcel en la que se han vistos presos los referidos actores, ya que ha provocado un "congelamiento" de la imaginación conceptual, trayendo como consecuencia que las injusticias o experiencias de discriminación innominadas no puedan ser articuladas, o incluso conceptualizadas, en términos de derechos. En efecto, el concepto de "derechos reproductivos", hasta entrado el siglo XX, había sido conceptualizado de manera confusa y además no eran judicializables ${ }^{95}$, lo que evidentemente perjudicó la reivindicación de las mujeres en esta materia.

En ocasiones, la falta de conceptualización ha provocado que intereses que no son los de las mujeres se superpongan a los de ellas, hasta hacerlos desaparecer, aun cuando estemos hablando de materias netamente de su incumbencia. En España, por ejemplo, a propósito de demandas de paternidad y manutención de los hijos, los actos discriminatorios contra las mujeres en estas materias, lamentablemente, no sirvieron para argumentar ni las peticiones de las demandantes, ni los fallos que resolvieron finalmente a su favor. Pese a que las sentencias pudieron favorecerlas, sus argumentos empezaban y terminaban en los intereses de los hijos, y la misma retórica se replicó en las sentencias. Es decir, no era tema el injusto impacto desigual de estos asuntos respecto de las mujeres, quedando así sin responder las preguntas de Rubio-Marín, sobre "¿qué pasa con el derecho de la mujer de no ser discriminada? ¿no es discriminación contra la mujer que debido a su biología se le fuerce a enfrentar daños sicológicos y esfuerzos materiales implicados por el cuidado de los hijos como madres solteras? (...) [Lo que demuestra] (...) que las mujeres aún tienen que apropiarse de los principios de igualdad y no discriminación para promover demandas que amplíen sus ámbitos de aplicación a cada esfera de sus vidas" ${ }^{\prime 96}$. Debe comprenderse que los temas que derivan de la sexualidad y la capacidad reproductiva de las mujeres tienen como telón de fondo su propia existencia, por tanto, aquellos deben analizarse y valorarse desde su propia experiencia,

95 IRVING (2008), p. 165.

96 Rubio-Marín (2005), p. 270. 
sin perjuicio de los intereses de los hijos, los que en todo caso no pueden sobreponerse a los de la madre hasta el punto de eclipsarlos.

La falta de conceptualización a causa de la invisibilización de los intereses y necesidades de las mujeres, se ha hecho evidente a la hora de debatir el derecho al aborto y darle un sustento jurídico, provocando que las mujeres recurran a otros derechos constitucionales, tales como la igualdad, la dignidad humana, la privacidad, la seguridad de las personas, la libertad, el libre desarrollo de la personalidad individual, la integridad síquica, física y moral, la libertad de pensamiento y creencia ${ }^{97}$. De hecho, en España, en 1985, cuando se debatía la ley que estableció los "abortos tolerados" (para evitar el peligro serio para la vida o salud de la madre, cuando el embarazo era resultado de una violación y cuando el feto tenía problemas serios físicos o discapacidades mentales), el Tribunal Constitucional declaró la constitucionalidad del derecho a acceder a estos por alguna de las causas permitidas, precisamente basándose en la noción de "autonomía individual", según es formulada por el derecho constitucional a la dignidad humana y el derecho para el libre desarrollo de la personalidad de cada uno, el derecho a la integridad física y moral, el derecho al honor, a la privacidad y a la propia imagen y la libertad de pensamiento o creencia. Queda claro entonces que la igualdad no tuvo cupo en esta ocasión, era muy temprano para que se vinculara esta materia con los impactos que podía tener en la vida de las mujeres, de manera tal de que estos cobraran el rol protagónico que les corresponde $^{98}$.

No obstante que en muchas ocasiones los resultados jurisdiccionales pueden ser favorables para las mujeres, el hecho de que un fallo se funde en uno $\mathrm{u}$ otro derecho no es indiferente. No es lo mismo resolver que una mujer tiene derecho a realizarse un aborto desde la perspectiva específica de las mujeres o de la igualdad de género, que fundar ese derecho en la privacidad, y que le estaría permitido entonces únicamente por encontrarse dicha decisión en aquel ámbito donde el Estado no puede entrar porque la Constitución ha levantado una cerca invisible, para que, precisamente éste no pueda hacerlo -tal como lo definió la Ministra Bertha Wilson en el caso R. v. Morgentaler ${ }^{99}$ de 1988, en donde la Suprema Corte canadiense derogó ciertas restricciones legislativas sobre el acceso al aborto, en aquellos aspectos en que fuera procedimentalmente ofensivo para el derecho a la vida, la libertad y la seguridad de las personas- ${ }^{100}$,

\footnotetext{
97 Baines y RUBio-Marín (2005), p. 17.

98 Rubio-Marín (2005), pp. 271 y 272.

99 Suprema Corte, 3 S.C.R. 463, 30 de septiembre de 1993. Puede consultarse el fallo aquí: http://www. canlii.org/en/ca/scc/doc/1993/1993canlii74/1993canlii74.html [visitado el 11/07/2014].

100 IRVING (2008), p. 208.
} 
omitiendo así cualquier referencia al derecho de la mujer de poder desplegar su dignidad y autonomía moral en igualdad de condiciones que el hombre.

En la jurisprudencia comparada encontramos innumerables casos que dan cuenta de la multiplicidad de argumentos jurídicos que sustentan el derecho de las mujeres para realizarse un aborto. En Canadá, por ejemplo, un médico acusado por realizar un aborto esgrimió que la criminalización del mismo atentaba "contra el derecho a la privacidad de las mujeres para tomar decisiones sin restricciones con respecto a su propia vida"101. Frente a ello, la Corte sostuvo que el argumento estaba basado en el artículo $7^{\circ}$ de la Carta de Derechos y Libertades de Canadá102, por tanto, que se fundaba en la vida, la libertad y la seguridad personal, dejando abierta la pregunta de si la Carta establecía o no un derecho a la privacidad. Más tarde, en otro fallo, luego de que la Corte afirmara que la prohibición del aborto atentaba contra la seguridad de las personas y la integridad física y sicológica de la mujer, la ministra Wilson agregó que "la disposición del aborto también priva a la mujer de su derecho de libertad, el cual definió en términos de autonomía personal sobre las decisiones íntimas importantes que afectan la vida privada de cada uno. [Sin embargo, no obstante que la jurisprudencia canadiense pareciese iluminar el camino para la reivindicación de los derechos sexuales y reproductivos de las mujeres,] estos casos no garantizan a las mujeres el derecho constitucional de sus propios cuerpos; desde esta perspectiva, la transformación social no es aún una realidad"103.

Por su parte, la instauración del derecho a la privacidad como fundamento para evitar la intervención del Estado en temas relacionados con los derechos sexuales y reproductivos de las mujeres, más precisamente, con el derecho a la anticoncepción y el acceso al aborto, tuvo lugar en el caso Griswold v. Connecticut ${ }^{104}$ cuando la Corte Suprema de EE.UU. estableció que, en virtud de aquel derecho, el Estado no podía penalizar los dispositivos anticonceptivos. Si bien la Constitución norteamericana no protegía expresamente el derecho a la privacidad, sostuvo la Corte, es cierto también que existen "garantías específicas en la carta de derechos [que] tienen zonas de penumbra, formadas por emanación de aquellas garantías que le ayudan a tener vida y sustancia"105.

\footnotetext{
101 BAINES (2005), p. 55.
}

102 “Todos tendrán el derecho a la vida, a la libertad y a la seguridad de su persona; y nadie podrá atentar contra este derecho, excepto cuando sea en conformidad con principios de justicia fundamental". Carta de Derechos y Libertades de Canadá, de 1982.

103 BAINES (2005), p. 57.

104 Suprema Corte, 381 U.S. 479, 7 de junio de 1965. Puede consultarse el fallo aquí: http://www.law. cornell.edu/supremecourt/text/381/479 [visitado el 2/07/2014].

105 Siegel (2005), p. 324. 
Luego, en 1973, el caso Roe v. Wade ${ }^{106}$ rescata la esencia de este criterio ya que la Corte fundó el derecho de la mujer de terminar o no su embarazo en el derecho a la privacidad. Al pronunciarse respecto de las teorías acerca de cuándo se inicia la vida, la Corte desconoce que el feto tenga el carácter de persona de conformidad a la enmienda decimocuarta, agregando a ello que no podía adoptar una teoría de la vida que invalidara "los derechos que están en juego de la mujer embarazada"107, lo cual nos da un indicio de que la mujer es vista como un agente moral titular de derechos que merecen protección y respeto, aun cuando esté embarazada, es decir, la posibilidad de defender una teoría que reconozca a la mujer como una mujer-vasija no es una opción admisible para la Corte. En su fallo, la Corte, en un intento de equilibrar los intereses de la madre y los del Estado de regular su conducta, extendió la aplicación del escrutinio estricto de la igual protección a los dos primeros trimestres, es decir, hasta que el feto sea viable, impidiéndole al Estado interferir en la voluntad de la madre durante ese período. Más adelante, el criterio establecido en Roe fue reafirmado y reformulado en Planned Parenthood v. Casey, profundizándose los motivos de la protección y respeto que merece a la privacidad y buscando sus fundamentos en otros valores constitucionales. En efecto, cuando la Corte afirma en Casey que "el Estado está obligado a respetar la decisión de la mujer embarazada sobre el aborto (...) [ya que su] destino (...) debe ser formado a la medida de su propia concepción de sus imperativos espirituales y su lugar en la sociedad, está reconociendo que más allá de su derecho a la privacidad, lo que fundamenta a su derecho a decidir, es la igualdad de los sexos, la igual posibilidad de cada sexo de desarrollarse como agentes morales. Con todo, Casey revirtió el criterio de la trimestralidad de Roe, y en el ánimo de conciliar los intereses de los estados con los de la madre, estableció que la Corte permitiría a los estados regular el aborto en resguardo de la protección de la vida del no nacido durante todo el embarazo, en la medida en que tal regulación no impusiera cargas excesivas en el derecho constitucional de las mujeres de tomar la decisión acerca de terminar su embarazo previo al punto de la viabilidad del feto (...) [Esto debía entenderse en el siguiente sentido. Si] una ley que sirve a un propósito válido (...) tiene el efecto incidental de hacer más difícil o más caro procurar un aborto no puede ser suficiente para invalidarlo. Solo cuando la regulación del estado impone una carga excesiva sobre la habilidad de una

106 Suprema Corte, 410 U.S. 113, 22 de enero, de 1973. Puede consultarse el fallo aquí: http://caselaw.lp. findlaw.com/scripts/getcase.pl?court=US\&vol=410\&invol=113\&friend=nytimes [visitado el 2/07/2014].

107 Siegel (2005), p. 325. 
mujer para tomar la decisión, hace que el poder del estado llegue al corazón de la libertad protegida por la cláusula del debido proceso"108.

Entre los casos mencionados, el más emblemático es Roe v. Wade, sin embargo, no obstante que el fallo fue positivo para la requirente, concordamos con Irving en que si nuestro norte es la igualdad y la equidad de género, y, si bien las mujeres necesitan "privacidad" con respecto a sus elecciones íntimas y reproductivas, las mujeres necesitan también estar protegidas por medidas positivas, incluyendo aquellas que reconocen el impacto de la capacidad reproductiva y la experiencia de ésta en sus vidas y bienestar"109, lo que necesariamente implica la consideración del respeto y promoción de la igualdad sustantiva a través de dichas medidas.

El problema de este argumento es que la privacidad ha servido históricamente para proteger la dominación masculina sobre la mujer y los hijos en la esfera del hogar, tal como ha sucedido en causas donde la cuestión principal es la inviolabilidad del hogar, y se le ha vinculado al derecho a la privacidad, en vez de apelar a otros derechos más pertinentes. Dadas sus variadas acepciones, la privacidad ha sido invocada en múltiples ámbitos, llegando a definiciones tan amplias como la que satisfizo al ministro Choudary en el caso Sareetha ${ }^{110}$, cuando afirmó que le bastaba "cualquier definición plausible de derecho de privacidad que obligue a tomar el cuerpo humano como su primera y más básica referencia para el control sobre la identidad personal. Tal definición, está obligada a incluir la inviolabilidad corporal y la integridad e intimidad de la identidad personal, incluyendo la privacidad marital. Lo anterior trae consecuencias nefastas para las mujeres, ya que "el concepto tradicional de 'privacidad marital' habla precisamente contra la libertad y la integridad corporal de ellas.

108 SiEGEL (2005), p. 326.

109 IRVING (2008), p. 210.

110 Sareethav. T. Venkata Subbaiah de 1983, fue un caso acerca de una popular actriz de cine, cuyo marido, que había sido indiferente frente a su partida hasta que se convirtió en famosa, la demandó solicitando restitución de los derechos conyugales. La Corte Superior de Andhra Pradesh, declaró inconstitucional esa parte de la ley de matrimonio que permitía solicitar la restitución, sobre la base de la privacidad y la igualdad de sexos. La referencia a la privacidad, fue la de más importancia y la base para la revocación final de la decisión de la Corte Suprema. Sin embargo, se desconoció el argumento de la igualdad construido por el Ministro Choudary, quien hizo notar que si bien el derecho era neutral a primera vista, aplicándolo a un marido o a una esposa, era discriminatorio debido a las sustantivas diferencias entre las posiciones sociales de los hombres y las mujeres en el matrimonio. La ejecución de tal normativa, planteó, alterará la vida de las esposa de un modo en que no podría posiblemente alterar la del marido Nussbaum (2005), p. 183. Suprema Corte de Andhra, AIR 1983 AP 356, 1 de julio de 1983. Puede consultarse el fallo aquí: http://www.indiankanoon.org/doc/1987982/ [visitado el 15/07/2014]. 
Lo cual hace difícil, incluso hoy en día, criminalizar la violación marital o la prosecución de la violencia doméstica"111.

Si nuestro propósito es darle un sentido feminista a la Constitución y, en consecuencia, procurar que la jurisprudencia se construya con miras a la equidad de género, no podemos satisfacernos solo con un fallo a favor del aborto, ya que es fundamental que los cimientos de esa resolución tengan en perspectiva los derechos humanos de las mujeres, y más precisamente, sus derechos sexuales y reproductivos, sin imponerles cargas motivadas en sus propiedades reproductivas. Decimos esto porque, en ocasiones, ciertos razonamientos pueden en el largo plazo perpetuar la desventaja en que se encuentran las mujeres en su quehacer de ser personas, tal como se observa en Nahmani v. Nahmani ${ }^{112}$ de 1984, un caso israelita donde se discutió el derecho que le asistía una mujer a la maternidad y, por otra parte, a su exmarido de no forzarlo a la paternidad. Ambos habían fecundado un óvulo de la mujer, con espermatozoides del ahora exmarido, depositándolo en un instituto médico de EE.UU., para inocularlos en una madre sustituta. Posteriormente, sin embargo, el hombre revocó su consentimiento para tal procedimiento, en circunstancias que la mujer deseaba perseverar en el proyecto. Así las cosas, el caso llegó hasta la Corte Suprema Israelí, la que falló a favor de la mujer estableciendo que "la paternidad era un componente de la dignidad humana (...) [provocando] un debate académico acerca de las dimensiones feministas del caso; mientras puede ser leído como una victoria para la opción individual de la mujer, la privacidad y la autonomía, también puede ser visto como una esencialización del rol de las mujeres como reproductoras biológicas ante todo ${ }^{113}$.

\subsection{La dignidad según el enfoque de las capacidades y el derecho a la igualdad como fundamento del derecho al aborto}

De conformidad con lo planteado, partimos de la idea de que las mujeres son seres oprimidos, pero no solo por la negación de la oportunidad de desarrollar las capacidades racionales para pensar y actuar, como lo señala Mill, es decir, no solo desde un enfoque kantiano dirigido hacia la racionalidad, sino también de acuerdo a la concepción de dignidad propio del enfoque de las capacidades.

\footnotetext{
111 Nussbaum (2005), p. 196.

112 Corte Suprema, CFH 2401/95, 12 de septiembre de1 1996. Puede consultarse el fallo aquí: http://ww3.lawschool.cornell.edu/AvonResources/RuthNahmaniv.DanielNahmani.pdf [visitado el 15/07/2014].

113 HiRSCHL y SHAChar (2005), p. 219.
} 
Las diferencias biológicas reproductivas entre hombres y mujeres acarrean para ellas perjuicios desde la perspectiva física -la carga corporal-y material. De ello ha sido capaz de hacerse cargo el enfoque de las capacidades. El derecho al aborto resulta mejor fundado en la dignidad humana, tal como lo señalamos anteriormente, si la consideramos de acuerdo a este enfoque, el cual, dando un paso al costado del enfoque kantiano que funda la dignidad solamente en la racionalidad, reconoce una variedad de maneras en que las leyes que restringen el aborto "pueden sobrecargar o violar la dignidad de las mujeres; al restringir la libertad y la decisión, pero también al dañar o arriesgar la salud, la integridad corporal, el bienestar emocional, las opciones de empleo y de asociación (...) La dirección política de esta concepción teórica es por tanto clara: las leyes no deberían simplemente proteger a las mujeres de una variedad de cargas; deberían crear capacidades de pleno derecho, u oportunidades para decidir, en cada área"114.

Este enfoque además pone sobre la mesa no solo el deber de no interferencia del Estado en las decisiones de las mujeres, sino también su deber positivo de velar por que, efectivamente, las opciones y la posibilidad de escoger cualquiera de ellas sea una realidad. Ello solo se logra garantizando el umbral mínimo conformado por las capacidades fundamentales que garanticen la autonomía necesaria para poder realizarse como ser humano, y atienda las desigualdades, puesto que estas últimas "tienen una importante relación con la autonomía [ya que] empañan el valor de la libertad para aquellos que están en peor situación"115, por lo que el Estado debe asumir su rol, bajo el propósito de respetar y promover la igualdad sustantiva. En este sentido, cobra importancia el financiamiento que preste el Estado para la práctica de los abortos, cuestión que ha sido problemática para los EE.UU., ya que después de la enmienda Hyde en el $77^{\prime}$ se restringió el acceso al aborto bajo programas federales Medicaid en todas las circunstancias, menos en las más extrema ${ }^{116}$.

El enfoque de las capacidades es pertinente también por cuanto vincula la dignidad con la igualdad humana. La garantía constitucional de la igualdad es violada cuando una medida afecta adversamente la dignidad individual. La misma conexión se ha elaborado en países como Canadá, Alemania y Sudáfrica. En el caso R. v. Morgentale, la ministra Wilson de la Corte Suprema Canadiense estableció que existe una "conexión estrecha entre la lucha por la dignidad humana y la igualdad de género, dado que para muchas mujeres la lucha por la defensa de los derechos reproductivos es paralela a las luchas anteriores de

114 Dixon y Nussbaum (2012), p. 69.

115 Holzleithner (2012), p. 24.

116 Dixon y Nussbaum (2012), pp. 75 y ss. 
los hombres para afirmar su humanidad y dignidad común contra un aparato estatal autoritario, de tal manera que el derecho a la reproducción o a no reproducir (...) es percibido apropiadamente como una parte integral de la lucha de la mujer moderna para afirmar su dignidad y valor como ser humano"117. En esta misma línea, la Corte Constitucional colombiana ha trazado el vínculo entre la igualdad y la dignidad en el entendido de que cuando un acto afecta la dignidad humana, necesariamente vulnera la igualdad. Así lo manifestó en el año 2001, conociendo de una tutela interpuesta por una trabajadora indígena, que prestaba servicios domésticos en un hotel y que reclamaba discriminación por la naturaleza de su empleo y su condición de indígena, ya que no se le permitía el uso del ascensor principal del establecimiento, obligándola a usar las escaleras pese a su mal estado de salud, pues el ascensor de servicio estaba con desperfectos. En su fallo ${ }^{118}$ la Corte admitió la tutela, aunque no por motivos de discriminación de género, sosteniendo que "el derecho fundamental a la igualdad fue violado por el simple acto de prohibirle a la mujer el uso de cualquier elevador como cualquier otro ser humano con igual dignidad"119.

Teniendo clara la visión ampliada de los perjuicios que sufren las mujeres por sus características biológicas reproductivas, de acuerdo a la idea de dignidad del enfoque de las capacidades, demos un paso más y establezcamos la perspectiva correcta desde la cual se debe mirar el embarazo, para poder fundamentar un derecho para las mujeres a la práctica de un aborto legal y seguro, teniendo en consideración la idea tras el voto disidente de Geduldig v. Aiello, en cuanto a la necesidad de reconocer, en virtud de la igual protección de la ley garantizada bajo la decimocuarta enmienda, las características físicas inexorablemente relacionadas a un sexo, para rescatar la diferencia, situándola en el contexto real de cada sexo, obligando a reflexionar en torno a las necesidades e intereses que surgen a propósito de las mismas.

La Corte Suprema de EE.UU. desarrolló, a propósito de demandas interpuestas por padres no casados que reclamaban derechos a favor de sus hijos o respecto de sus hijos, un test para determinar los derechos parentales, el cual comprendía un vínculo biológico y una relación permanente con el hijo. Es decir, observó al embarazo desde una perspectiva relacional que implicaba una cuestión biológica, pero también afectiva. A diferencia de la opinión de muchas feministas, Jennifer Hendricks ha planteado lo positivo de esta teoría, señalando que "negar el componente relacional del embarazo saca al aborto

117 Dixon y Nussbaum (2012), p. 78.

118 Corte Constitucional, T-1042/01, 28 de septiembre de 2001. Puede consultarse el caso aquí: http:// www.corteconstitucional.gov.co/relatoria/2001/t-1042-01.htm [visitado el 15/07/2014].

119 Morgan (2005), p. 86. 
de otros asuntos sobre libertad reproductiva, distancia el discurso del aborto de las experiencias reproductivas de las mujeres, y socava las demandas legales de las mujeres en otros contextos. Reconocer el embarazo como una condición biológica y una relación de cuidado permanente provee una sólida base para analizar la libertad reproductiva de las mujeres y la igualdad"120.

Si bien la Corte había tenido una postura a propósito de las diferencias biológico-reproductivas de los hombres y las mujeres, la cual implicó que, en casos como Geduldig revisado anteriormente, la igualdad formal se aplicara en su versión más estricta posible, en Stanley v. Illinois ${ }^{121}$ ésta cambió a propósito de las demandas de padres no casados, ya que no se conformó con la idea de que ellos estuvieran biológicamente situados en un lugar distinto, sino que hizo una aplicación sustantiva del principio de igualdad, demandando la paridad de resultados que compensarían la desventaja biológica de los hombres. Luego, la diferencia entre hombre y mujer acababa cuando el padre demostraba que había establecido una relación parental con el hijo. Desde ahí entonces, los derechos parentales del padre le son protegidos como una cuestión de igualdad de sexo.

Lo interesante de esta nueva postura es que la Corte hace un reconocimiento de la relación maternal/paternal que surge en el embarazo y posterior a él también. Es decir, el embarazo no solo implica una consecuencia biológica que únicamente afecta a la madre, sino que trae aparejado una relación emocional con la criatura que nace a la vida. Este reconocimiento judicial nutre argumentalmente lo planteado acerca de que el embarazo compromete distintos espacios en la vida de la mujer, de acuerdo a la idea de la dignidad, según el enfoque de las capacidades. Y esta misma perspectiva subjetiva del embarazo, ha sido recogida por parte de la jurisprudencia canadiense, tal como lo ha demostrado Bertha Wilson, al manifestar que las restricciones al aborto que importan una violación de los derechos fundamentales atentan contra el imperativo categórico kantiano de tratar a las personas como fines en sí mismos y no como medios, violando con ello la dignidad y autoestima. De este modo, la ministra devela el "contexto subjetivo de las mujeres embarazadas [e] inyecta un nuevo humanismo y contextualismo en las decisiones adoptadas por la Corte Suprema de Canadá"122.

Esta perspectiva biológico-relacional del embarazo, nos permite sortear la fragilidad de ciertos argumentos que se esgrimen para justificar el derecho al aborto, complementándolos. Tal es el caso del que apunta a la carga física del

\footnotetext{
120 Hendricks (2012), pp. 264 y ss.

121 Suprema Corte, 405 U.S. 645, 3 de abril de 1972. Puede consultarse el fallo aquí: http://caselaw. Ip. findlaw.com/scripts/getcase.pl?court=US\&vol=405\&invol=645 [visitado el 2/07/2014].

122 IRVING (2008), p. 143.
} 
embarazo. Judith Jarvitz Thompson se ha convertido en su eximia expositora, a través de la analogía de la persona que es raptada por la Sociedad de Amantes de la Música para servir de apoyo a un violinista famoso, quien solo puede sobrevivir si la victima raptada se mantiene conectada a él por nueve meses ${ }^{123}$. A pesar de lo ilustrativa que puede ser la analogía, lo frágil de ella es que descansa su fuerza argumentativa en la carga física que la mujer debe soportar durante el embarazo, situación a la que jamás un hombre se enfrentaría, y por tanto, se le vulneraría la igual protección. Si bien este argumento expone las exigencias exageradas que supone un embarazo forzado, cuestión que merece todo nuestro interés y atención, de todas formas resulta incompleto, ya que "el derecho a realizarse un aborto no es solo sobre el cuerpo [sino] (...) sobre el curso completo de la vida de la mujer [quien, de llevar adelante un embarazo forzado, no solo se someterá a exigencias físicas extremas, incomparables con cualquier situación a la que se le pudiese someter en contra de su voluntad a un hombre, por invocación de sus propiedades biológicas, sino que además, se le involucrará en una relación maternal de la que no quiere ser parte. De hecho, una de las razones por las que las mujeres se realizan abortos no es] (...) por la carga física típica del embarazo; las mujeres se hacen abortos para evitar la maternidad"124. Sobre esto último, cabe tener presente que la "maternidad está lejos de ser solo una vivencia individual y es, en cambio, un continente de simbolizaciones/representaciones sociales, prácticas y relaciones en torno al cuerpo de las mujeres, la reproducción y la dependencia o el cuidado"125.

Otro argumento cuya fragilidad es posible sortear a propósito de la postura planteada por la Corte, es relativo a las cargas sociales de la maternidad, apuntando directamente a la igualdad sexual. Este argumento, con todo lo útil que puede llegar a ser para evidenciar la desigualdad sexual en la sociedad, resulta débil para poder fundar la libertad reproductiva como derecho humano. Y es que si la desigualdad socio-económica es el argumento para justificar el derecho al aborto, ¿qué sucederá cuando en algún momento se llegue a la efectiva igualdad en ese ámbito? ¿Cuál será el sustento para este derecho? En definitiva, centrarse en estos argumentos, deviene en inevitable la comparación entre las cargas sociales de la maternidad con las de la paternidad, provocando una desconexión entre el derecho al aborto y los cuerpos de las mujeres, planteado al primero como un derecho a evitar la maternidad en condiciones de desigualdad, motivo por el cual esta explicación resulta inadecuada para la

123 Para una mejor comprensión véase ThOMson (1992), pp. 143-159.

124 Hendricks (2012), p. 273.

125 ZÚÑIIGA AÑAZCo (2013), p. 270. 
elaboración de los derechos humanos reproductivos de las mujeres los cuales buscan eliminar, precisamente, esa desigualdad ${ }^{126}$.

De acuerdo a lo anterior, el enfoque relacional del embarazo, que supone integrar lo biológico con lo social, se aparta de estos argumentos que consideran solo parcialmente las formas en que un embarazo forzado puede dañar la dignidad humana y vulnerar la igualdad de las personas. En este sentido, una perspectiva más unificadora es más útil, ya que la sociedad considera a las mujeres embarazadas que son madres desde el período del embarazo en adelante, imponiéndoles las exigencias que ello supone, cuestión que no sucede con los padres, o por lo menos no de la misma forma. Además de ello, continúa Hendricks, la relación entre la madre y el hijo y el padre y el hijo, son diferentes porque la sociedad también las ha construido diferentes. La primera relación, en el caso de un embarazo forzado, la autora la compara con el síndrome de Estocolmo, el cual afecta a quienes son rehenes de las necesidades de otra persona y que empiezan a generar empatía con su captor, generándose preferencias adaptativas (en el sentido explicado más arriba) para sobrevivir a la situación. A juicio de la autora, la mujer que lleva adelante un embarazo forzado "está físicamente raptada para servir a los intereses del estado que pretende estar actuando a favor del feto (...) [lo que] la obliga a desarrollar una postura psicológica hacia el feto y el eventual niño (...) [Luego, a modo de supervivencia psicológica/emocional, si la madre es forzada a llevar un embarazo a término] es preferible (...) que desarrolle una identificación positiva con el niño, ya sea si ella misma cría al niño o si encuentra un hogar diferente" ${ }^{\prime 127}$.

Esta analogía permite identificar el perjuicio no solo físico que afecta a las mujeres sino también emocional derivado de la relación que surge, inevitablemente, con la criatura que lleva en su vientre, la que se ve fuertemente influenciada por los paradigmas sociales-sexuales de desigualdad, resultando consistente entonces la teoría del embarazo relacional con el derecho al aborto por cuanto, cuando una mujer opta por realizarse uno, está eludiendo la maternidad, y esto lo quiere hacer del modo más rápido y seguro posible, antes de que la relación pueda comenzar. "El daño de un embarazo forzado, no es solo la invasión física invocada por analogía del violinista de Thompson, sino también la creación de una fuerte relación emocional de identificación"128.

126 HeNDRICKS (2012), p. 277.

127 Hendricks (2012), p. 278.

128 Hendricks (2012), p. 279. 


\section{Conclusiones}

A lo largo de este trabajo hemos buscado entregar herramientas al intérprete constitucional para que, mediante una aplicación vigorosa de la cláusula de igualdad, se pueda generar un bloque de constitucionalidad que contribuya a difuminar la falsa neutralidad de las reglas que pertenecen a un orden jurídico inserto en un sistema de control patriarcal. Dado que dicha cláusula opera como un mandato abierto o de optimización, el rol que cumpla la jurisdicción de naturaleza constitucional puede llegar a ser decisivo para articular una adecuada comprensión de un principio de igualdad que recoja la perspectiva de género desde el enfoque de las capacidades de Nussbaum, especialmente mientras no se incorporen modificaciones estructurales al ordenamiento jurídico o los operadores no internalicen las asimetrías de género. Para lograrlo, hemos ilustrado críticamente el modo en que la jurisprudencia comparada ha resueltos algunos pleitos en los que está en juego tal perspectiva, para concentrarnos-acto seguido- en las razones que nos permiten justificar un reconocimiento constitucional de los derechos sexuales y reproductivos de las mujeres como una especificación decisiva del principio de igualdad interpretado en clave de género.

Para los propósitos planteados para este trabajo, acogemos la teoría del embarazo relacional y su fundamento, basado en la obligación de velar por la igualdad sustantiva reconociendo las consecuencias que traen aparejadas las diferencias biológico-reproductivas de cada sexo, para justificar el derecho a un aborto legal y seguro. En efecto, tal como lo ha planteado la Convención de Derechos Humanos, los temas relacionados específicamente con las mujeres, como el caso del aborto, exigen enfoques distintos de los basados en la interpretación absoluta de la igualdad.

Lo anterior va de la mano del reconocimiento de que la igualdad sustantiva tiene un rol transformador, por lo que debe operar en beneficio de los grupos oprimidos -como las mujeres- para compensar la histórica discriminación de la cual han sido objeto. Luego, teniendo clara la necesidad de buscar una igualdad real y efectiva, el enfoque de las capacidades permite visibilizar mejor el extenso ámbito de niveles en los que operan las desigualdades entre hombres y mujeres y, en particular, lo que implica la criminalización del aborto al no limitar la argumentación al impedimento de ejercer el derecho a decidir y planificar la vida, sino tomando en consideración aquellos aspectos de la misma que dicen relación con las emociones y las relaciones interpersonales, las que se ven comprometidas en esta situación. La necesidad de la constitucionalización de los derechos sexuales y reproductivos, en los cuales se enmarca el derecho al aborto, sale a flote, incluso, aunque no lo pretendiéramos así, si miramos la constitución como una herramienta funcional para los propósitos feministas, acortando así la brecha entre las mujeres y la comunidad constitucional que les debería-también- pertenecer. 
Es preciso, plantea Carl Coleman, que el derecho al aborto sea visto como un imperativo social, tanto como un asunto de opción individual y subjetiva. En muchas ocasiones, incluso cuando el aborto es legal, éste no resulta ser una opción verdadera para las mujeres. De hecho, "hablar de opción, trivializa la presión e individualiza la decisión (...) A pesar de que la decisión debe ser tomada por la mujer en la medida que se le proteja su autonomía y dignidad, a menudo no es tomada solo por ella"129. Esto nos lleva a reafirmar la idea de la necesidad de constitucionalizar los mencionados derechos, pues hablamos de asuntos que, pese a que forman parte de la intimidad del ser humano, son tan fundamentales respecto de ellos/as, que resultan ser, en verdad, de interés público ya que su vulneración afecta los derechos fundamentales a la igualdad y la dignidad humana, de acuerdo a lo señalado a lo largo de este trabajo. Por lo mismo, ya que involucran aspectos esenciales de la vida de las personas deben ser abordados a ese nivel, y el sitio jurídico por antonomasia donde se reconocen y se mandan respetar y promover los derechos básicos de las personas son las cartas fundamentales.

Lo que nos convoca en esta reflexión son ciertos derechos de índole humana y, por tanto, fundamentales. Hemos hablado de la igualdad (en su versión sustantiva) y la dignidad humana, moduladas desde el enfoque de las capacidades. Si no se enfrenta el problema desde esta perspectiva, cuando se trata del ejercicio de los derechos sexuales y reproductivos de las mujeres, seremos ciegos ante aquellas condiciones que justifican las circunstancias a tener en cuenta para reconocerles la plena pertenencia a la comunidad moral y constitucional. De no ser así, tal como ha sucedido sistemáticamente en Chile (veremos qué sucede con el proyecto prometido sobre legalización del aborto terapéutico) solo resta pensar que, producto de su condición de seres oprimidas, las mujeres deben considerarse como medios, en vez de fines en sí mismas, para satisfacer las moralidades de la élite política y religiosa. Es decir, no deben ser tratadas con igual consideración y respeto que los hombres cuando se trata de ejercer sus derechos sexuales y reproductivos, sino, simplemente, deben ser tratadas como algo menos que seres humanos, ya que al vulnerarles su derecho fundamental a la igualdad y la dignidad humana, se les despoja de aquello que las hace titular de las mismas ${ }^{130}$, de lo que las faculta precisamente para ser personas, lo que constituye, no solo desde una perspectiva moral sino también jurídica, una aberración.

129 IRVING (2008), p. 211.

130 Sobre qué hace que una persona humana tenga la condición de tal, véase VILLAVICENCIO (2008) pp. 33-51. 


\section{Bibliografía CITADA}

Aguilera, Daniela, VÁsquez, Andrea y ZúñIga Fajurı, Alejandra (2007): “Lejos del poder. Hacia la implementación de una ley de cuotas en Chile", en: Revista de Derecho (Valdivia) (volumen XX, № 2), pp. 9-30.

Alexy, Robert (2008): Teoría de los derechos fundamentales, $2^{\mathrm{a}}$ ed., (Traducc. de Carlos Bernal Pulido, Madrid, Centro de Estudios Políticos y Constitucionales).

Arango Olaya, Mónica (2004): "El bloque de constitucionalidad en la jurisprudencia de la Corte Constitucional colombiana", en: Revista Precedente, pp. 79-102.

BAINES, Beverly (2005):"Using the Canadian Charter of Rights and Freedoms to constitute women", en: Beverly Baines y Ruth Rubio-Marín (Ed.), The Gender of Constitutional Jurisprudence (Traducc. Cambridge UniversityPress), pp. 48-74.

BaINES, Beverly y Rubio-Marín, Ruth (2005): "Introduction: toward a feminist constitutional agenda", en: Beverly Baines y Ruth Rubio-Marín (Ed.), The Gender of Constitutional Jurisprudence (Traducc. Cambridge University Press), pp. 1-21.

Dixon, Rosalind y Nussbaum, Martha (2012): "Abortion, Dignity and a Capabilities Approach", en: Beverley, Baines; Daphne Barak-Erez y TsviKahana (Eds.), Feminist Constitutionalism. Global Perspectives (Traducc. Nueva York, Cambridge University Press) pp. 64-80.

Elver, Hilal (2005): "Gender equality from a constitutional perspective: the case of Turkey", en: Beverly Baines y Ruth Rubio-Marín (ED.), The Gender of Constitutional Jurisprudence (Traducc. Cambridge University Press), pp. 278-305.

FACIO, Alda; JiméneZ, Rodrigo y Morgan, Martha (2005): "Gender Equality and International Human Rights in Costa Rican Constitutional Jurisprudence", en: Beverly Baines y Ruth Rubio-Marín (Ed.), The Gender of Constitutional Jurisprudence (Traducc. Cambridge University Press) pp. 99-121.

FiguerOA, Rodolfo (1996): "Igualdad y Discriminación". Disponible en:http:// www.derechoshumanos.udp. cl/wp-content/uploads/2009/07/ihualdad-yno-discrim.pdf [visitado el 14/09/2012].

FigueroA, Rodolfo (2007): "Concepto de persona, titularidad del derecho a la vida y aborto", en: Revista de Derecho (Valdivia) (volumen XX, № 2), pp. 95-130.

FigueroA, Rodolfo (2013) "La moralidad del aborto: ampliando la discusión", en: Acta Bioethica (volumen XIX No 1), pp. 105-112.

FigueroA, Rodolfo (2014) “¿Son constitucionales las cuotas de género para el Parlamento?, en: Revista Chilena de Derecho, aceptado. 
HAY, Carol (2013): Kantianism, Liberalism and Feminism. Resisting Oppression (New York, Palgrave Macmillan).

HendRICKS, Jennifer S. (2012): "Pregnancy, equality, and U.S. constitutional law", en: Beverley Baines; Daphne Barak-Erez y TsviKahana (Eds.), Feminist Constitutionalism. Global Perspectives (Nueva York, Cambridge University Press), pp. 263-280.

HIRSCHL, Ran y SHACHAR, Ayalet (2005): "Constitutional Transformation, Gender Equality, and Religious/National Conflict in Israel: Tentative Progress through the Obstacle Course" en: Beverly Baines y Ruth Rubio-Marín (Ed.), The Gender of Constitutional Jurisprudence (Nueva York, Cambridge University Press), pp. 205-229.

HolzleitHner, Elisabeth (2012): "Interrogating Exit in Multiculturalist Theorizing: Conditions and Limitations", en: Dagmar Borchers y Annamari Vitikainen (Eds.), On Exit. Interdisciplinary Perspective on the Right of Exit in liberal Multicultural Societies (Berlin, De Gruyter), pp. 13-33.

IRVING, Helen (2008): Gender and the Constitution. Equity and Agency in comparative constitutional design (Nueva York, Cambridge University Press).

KarPIN, Isabel y O'ConnelL, Karen (2005): "Speaking into a Silence: Embedded Constitutionalism, the Australian Constitution, and the Rights of Women" en: Beverly Baines y Ruth Rubio-Marín (Ed.), The Gender of Constitutional Jurisprudence (Cambridge University Press), pp. 22-46.

LAPORTA, Francisco (1985): "El principio de igualdad. Introducción a su análisis", en: Sistema. Revista de Ciencias Sociales ( $\left.N^{\circ} 67\right)$, pp. 3-31.

Mena, Francisco (2012): "La sentencia A, B y C contra Irlanda y la cuestión del aborto: ¿Un "punto de inflexión" en la jurisprudencia de la Corte Europea de Derechos Humanos en materia de consenso y margen de apreciación nacional?, en: Anuario de Derechos Humanos (No 8), pp. 115-124.

MorGan, Martha I (2005): "Emancipatory Equality: Gender Jurisprudence under the Colombian Constitution" en: Beverly Baines y Ruth Rubio-Marín (Ed.), The Gender of Constitutional Jurisprudence (Cambridge University Press), pp. 75-97.

Nussbaum, Martha (2000): Women and Human Development: The Capabilities Approach (Nueva York, Cambridge University Press).

Nussbaum, Martha (2005): "India, Sex Equality, and Constitutional Law" en: Beverly Baines y Ruth Rubio-Marín (Ed.), The Gender of Constitutional Jurisprudence (Nueva York, Cambridge University Press) pp. 174-203.

Ossandón, María Magdalena (2012): "Aborto y Justificación", en: Revista Chilena de Derecho (volumen XXXIX, № 2), pp. 325-369.

Peces-Barba, Gregorio (1991): "La igualdad" en Curso de Derechos Fundamentales (I) (Madrid, Eudema) pp. 242-251. 
Purol, Ángel (2010): El sueño de la igualdad de oportunidades. Crítica de la ideología meritocrática (Barcelona, Gedisa).

Rodríguez, Blanca y SACKSOFSKY, Ute (2005): "Gender in the German Constitution", en: Beverly Baines y Ruth Rubio-Marín (Ed.), The Gender of Constitutional Jurisprudence (Nueva York, Cambridge University Press), pp. 149-173.

Rubio-Marín, Ruth (2005): "Engendering the Constitution: The Spanish Experience", en: Beverly Baines y Ruth Rubio-Marín (Ed.), The Gender of Constitutional Jurisprudence (Nueva York, Cambridge University Press), pp. 256-277.

Ruiz Miguel, Alfonso (1996): "La discriminación inversa y el caso Kalanke", en: Doxa (No 19), pp. 123-140.

Siegel, Reva B. (2005): "Gender and the United States Constitution: equal protection, privacy, and Federalism", en: Beverly Baines y Ruth Rubio-Marín (Ed.), The Gender of Constitutional Jurisprudence (Nueva York, Cambridge University Press) pp. 306-332.

Singer, Peter (1995): Ética Práctica, $2^{a}$ ed., (Traducc. Rafael Herrera Bonet, New York, Cambridge University Press).

SMITH, Nicholas Mark (2011): Basic Equality and Discrimination. Reconciliation the Theory and Law (Reino Unido, Ashgate).

Thomson, J.J. (1992): "Una defensa del aborto", en: Debate sobre el aborto, cinco ensayos de filosofía moral (Madrid, Cátedra), pp. 143-159.

Valenzuela, Cecilia y ZúñIga Fajurı, Alejandra (2014): "Leyes de cuotas electorales, constitución y democracia", en: Revista de Derecho (Valdivia), en prensa.

Villavicencio Miranda, Luis (2008): “¿Derechos para quiénes? Reflexiones sobre algunas cuestiones embarazosas", en: Revista de Derecho de la Universidad Austral de Chile (volumen XXI, No 2), pp. 33-51.

Young, Iris (2000): La justicia y la política de la diferencia (Traducc. Silvina Álvarez, Madrid, Ediciones Cátedra).

ZúñIGa Fajurı, Alejandra (2011): "Aborto y derechos humanos", en: Revista de Derecho (Valdivia), (volumen XXVI, No 2) pp. 163-177.

ZúNíiga AÑAZCO, Yanira (2005): "Democracia paritaria: de la teoría a la práctica", en: Revista de Derecho (Valdivia) (volumen XVIII, No 2), pp. 131-154.

ZúÑIGA AÑAZCO, Yanira (2006): "El derecho como representación-deformación. Un análisis de su construcción adversarial en clave de género y derechos fundamentales", en: Revista de Derecho (Valdivia) (volumen XIX, № 1), pp. 35-59.

ZúÑIGA AÑAZCO, Yanira (2009): "La 'generización' de la ciudadanía. Apuntes sobre el rol de la diferencia sexual en el pensamiento feminista", en: Revista de Derecho (Valdivia) (volumen XXII, No 2), pp. 39-64. 
ZúNíga AÑazco, Yanira (2010): "Ciudadanía y género. Representaciones y conceptualizaciones en el pensamiento moderno y contemporáneo", en: Revista de Derecho Universidad Católica del Norte (Año 17, №2), pp. 133-163.

ZúÑIGA AÑAZCO, Yanira (2013): “Una propuesta de análisis y regulación del aborto en Chile desde el pensamiento feminista", en: Revista lus et Praxis (año 19, $\mathrm{N}^{\circ}$ 1), pp. 255-300.

JURISPRUDENCIA CITADA

Griswold v. Connecticut, 381 U.S.- 479 (1965).

Stanley v. Illinois, 405 U.S. 645 (1972).

Roe v. Wade, 410 U.S. 113 (1973).

Geduldig v. Aiello, 417 US- 484 (1974).

Sareethav. T. Venkata Subbaiah, AIR 1983 AP 356 (1983).

Planned Parenthood v. Casey, 505 U.S. 833 (1992).

R. v. Morgentaler, [1993] 3 SCR 463, 1993 CanLII 74 (SCC).

Sala Constitucional de la Corte Suprema de Justicia de Costa Rica, Decisión No 3150-94 (1994).

Contraloría General de la República, Dictamen Nº 25.403, de 21 de agosto de 1995.

Nahmani v. Nahmani, CFH 2401/95 Corte Suprema de Israel, (1996).

Sentencia C-013 de 1997, Corte Constitucional de Colombia, M.P. José Gregorio Hernández Galindo.

United States v. Morrison et al., 529 U.S. 598 (2000).

Sentencia T-1042 de 2001, Corte Constitucional de Colombia, M.P. Manuel José Cepeda Espinosa.

Tribunal Constitucional de Chile, rol No 740-07-CDS, de 18 de abril de 2008.

Corte Interamericana de Derechos Humanos, Artavia Murillo y otros ("fecundación in vitro") vs. Costa Rica, sentencia de 28 de noviembre de 2012. 